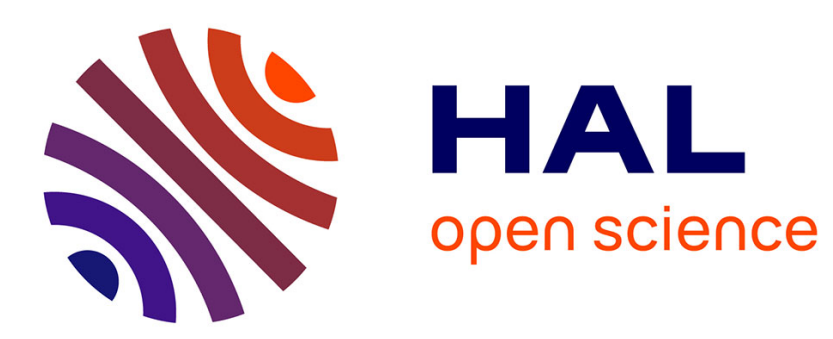

\title{
Lifelong endocrine fluctuations and related cognitive disorders.
}

\author{
Marie-Laure Ancelin, Karen A. Ritchie
}

\section{To cite this version:}

Marie-Laure Ancelin, Karen A. Ritchie. Lifelong endocrine fluctuations and related cognitive disorders.. Current Pharmaceutical Design, 2005, 11 (32), pp.4229-52. inserm-00243083

\section{HAL Id: inserm-00243083 https://www.hal.inserm.fr/inserm-00243083}

Submitted on 13 Nov 2009

HAL is a multi-disciplinary open access archive for the deposit and dissemination of scientific research documents, whether they are published or not. The documents may come from teaching and research institutions in France or abroad, or from public or private research centers.
L'archive ouverte pluridisciplinaire HAL, est destinée au dépôt et à la diffusion de documents scientifiques de niveau recherche, publiés ou non, émanant des établissements d'enseignement et de recherche français ou étrangers, des laboratoires publics ou privés. 


\section{HAL author manuscript}

\section{LIFELONG ENDOCRINE FLUCTUATIONS AND RELATED COGNITIVE DISORDERS}

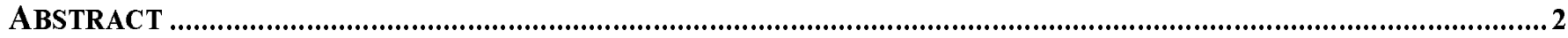

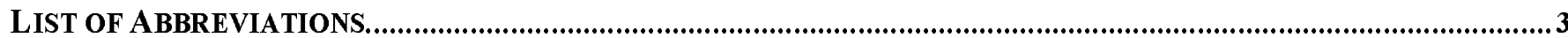

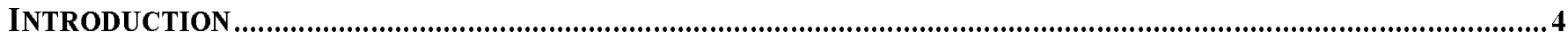

I. MECHANISMS OF GONADAL HORMONE EFFECTS ON COGNITION.........................................................................4

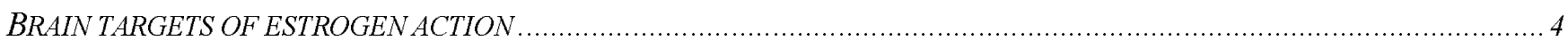

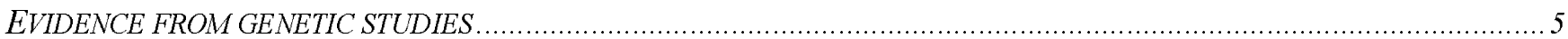

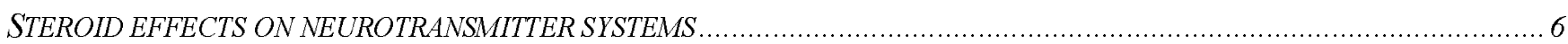

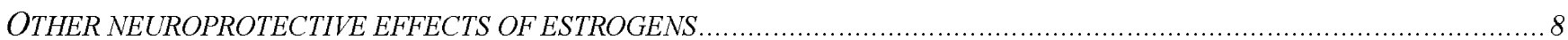

II. HORMONAL EXPOSURE ACROSS THE LIFE-SPAN AND EFFECTS ON COGNITIVE FUNCTIONING ..........................9

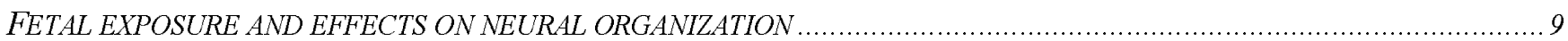

PUBERTY AND ADULT DEVELOPMENT AND OBSERVED SEX DIFFERENCES IN COGNITIVE FUNCTIONING ..................... 10

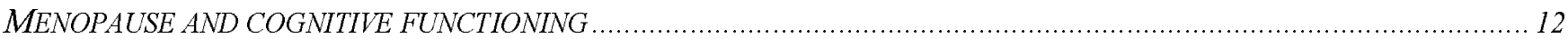

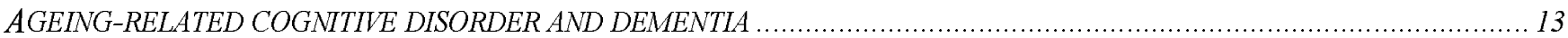

ENDOCRINE FLUCTUATIONS AND COGNITIVE FUNCTIONING: A CONTINUUMMODEL ........................................ 14

III. EXOGENOUS HORMONAL EFFECTORS AND COGNITION .................................................................................... 15

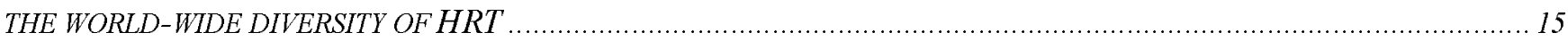

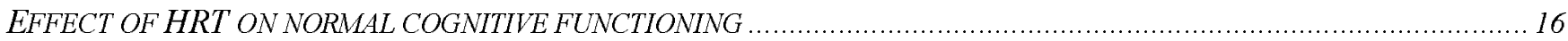

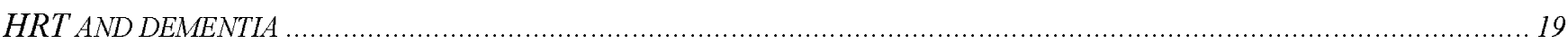

Preventive effect on Alzheimer's disease: observation studies...................................................................... 19

Preventive effect on Alzheimer's disease: The specificities of the WHIMS RCT …......................................22

Effect of HRT on the severity of Alzheimer's disease ......................................................................................22

STUDY LIMITATIONS AND VARIABILITY AS THE PRINCIPAL CAUSE OF INCONSISTENCIES IN RESULTS..........................23

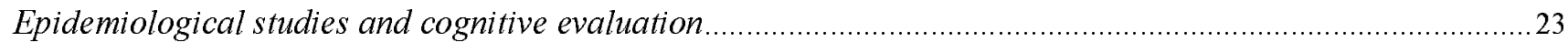

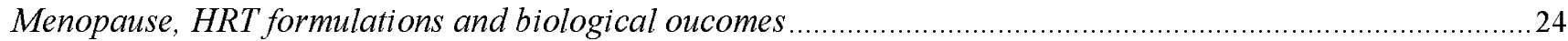

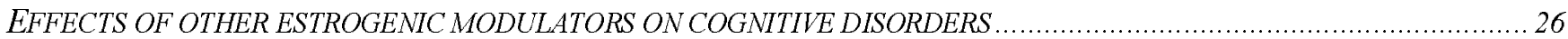

IV. PHYSIOLOGICAL MARKERS ASSOCIATED WITH LIFELONG CUMULATIVE ESTROGEN EXPOSURE ...................28

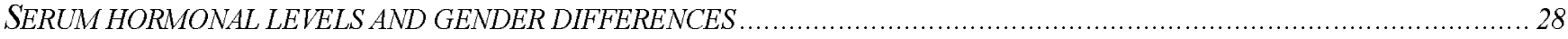

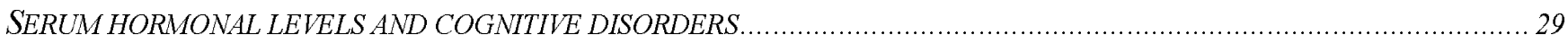

PHYSIOLOGICAL MARKERS ASSOCIATED WITH LIFELONG ESTROGEN FLUCTUATION ….............................................. 31

V. TOWARDS AN INTEGRATIVE MODEL OF CUMULATIVE ESTROGEN EXPOSURE....................................................33

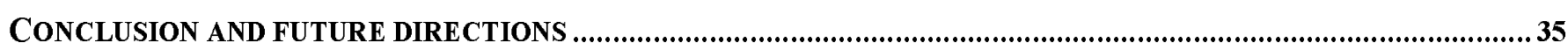

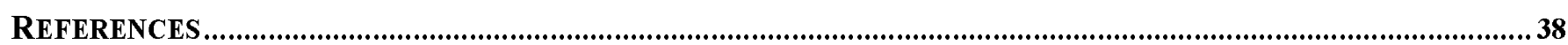




\section{LIFELONG ENDOCRINE FLUCTUATIONS AND RELATED COGNITIVE DISORDERS}

\section{M.L. ANCELIN* \& K. RITCHIE}

Inserm E 0361, Epidemiology and Clinical Research in Nervous System Pathologies, Hôpital La Colombière, Pavillon 42, 39 avenue Charles Flahault, BP 34493, 34093 Montpellier Cedex 5, France

Tel: 3304996145 60; Fax: 3304996145 79; Mail: ancelin@montp.inserm.fr

\section{$\underline{\text { ABSTRACT }}$}

The aim of this review is to examine the relationship between endocrine fluctuation and cognitive functioning. A plethora of in vitro and in vivo studies have demonstrated the neuroprotective role of estrogens and their impact on the neurotransmitter systems implicated in cognition. Recent hormonal replacement therapy (HRT) trials in nondemented post-menopausal women suggest a temporary positive effect (notably on verbal memory), and four recent meta-analyses converge to suggest a possible protective effect in relation to Alzheimer's disease (reducing risk by 29 to 44\%). However, data from the only large randomized controlled trial published to date, the Women's Health Initiative Memory Study, did not confirm these observations and have even suggested an increase in dementia risk for women using HRT compared to controls. Several methodological differences between observation studies and controlled trials with regard to patient group, type, timing and duration of HRT, cognitive measures and analyses, are discussed to explain these discrepancies. The association between hormonal serum level and cognitive functioning remains controversial suggesting high inter-individual vulnerability in risk. Moreover, research on the impact of endocrine functioning on cognition during the female reproductive cycle suggests lifelong fluctuations in vulnerability. Etiological models taking into account the interaction of clinical, reproductive, and menstrual events throughout life may provide a more valid approach in understanding the effects of steroids on the brain and in determining sub-groups at heightened risk. Cognitive disorders in the elderly are more likely be related to cumulated lifelong exposure to steroids, rather than to a specific exposure to a given steroid. Multifactorial models based on an exhaustive view of all hormonal events throughout reproductive life together with other risk factors (notably genetic risk factors related to estrogen receptor polymorphisms) should be explored to clarify the role of hormonal risk factors, or protective factors for cognitive dysfunction and dementia.

Key words: cognition, Alzheimer's disease, estrogens, female reproductive cycle, menopause, hormone replacement therapy, cumulated lifelong exposure to steroids. 


\section{LIST OF ABBREVIATIONS}

AD: Alzheimer's disease

AMPA: amino 3 hydroxy 5 methylisoxazole 4 propionate

ApoE: apolipoprotein E

APP: amyloid precursor protein

$A \beta$ : amyloïd $\beta$

BDNF: brain derived neurotrophic factor

BMD: bone mineral density

CEE: conjugated equine estrogens

CNS: central nervous system

Co-STAR: study of tamoxifen and raloxifen/ cognition

CREB: cAMP responsive-element binding protein

CRP: $C$ reactive protein

DA: dopamine

DES: diethylstilbestrol

ER: estrogen receptor

ERT: estrogen replacement therapy

FSH: follicle stimulating hormones

GABA: $\gamma$-aminobutyric acid

$\mathrm{GnRH}$ : gonadotropin releasing hormone

HDL: high density lipoprotein

HR: hazard ratio

HRT: hormone replacement therapy

LDL: low density lipoprotein

LH: luteinizing hormones

MAO: monoamine oxidase

MAPK: mitogen activated protein kinase

(m)MMSE: (modified) mini-mental status examination

MPA: medroxyprogesterone acetate

NA: noradrenaline

NGF: nerve growth factor

NMDA: N-methyl-D-aspartate

OC: oral contraceptive

OR: odd ratio

PET: positron emission tomography

PI3K: phosphatidylinositol 3-kinase

PREPARE: preventing postmenoapusal memory loss and Alzheimer's disease with replacement estrogens

RCT: randomized controlled trial

SERM: selective estrogen receptor modulator

SPECT: single photon emission computed tomography

WHI(M)S: women's health initiative (memory) study

WISDOM: women's international study of long duration oestrogen after menopause

5-HT: serotonin 


\section{INTRODUCTION}

The significantly higher prevalence of Alzheimer's disease (AD) in post-menopausal women observed in most western countries has led to increasing interest in the role of gonadal hormones, and in particular estrogen, in cognitive functioning. Given that estrogen receptors are extensively present in brain tissue, a world-wide debate is currently underway concerning the potential value of hormonal replacement therapy (HRT) in reducing ageingrelated cognitive changes, and delaying, if not preventing, the onset of dementia. Recent findings from the largest to date randomised placebo controlled HRT trial including over 4,000 women have suggested, however, that HRT may have a harmful effect on cerebro-vascular systems and cognitive functioning, and may even increase risk of dementia. These findings have forced us to review previous evidence for a protective effect and to develop more robust epidemiological models of risk.

In this review we argue that the most serious short-coming of previous studies has been their focus on hormonal changes after the menopause, without taking into account individual life-time exposure to hormonal variability, and that many of the inconsistencies found between studies may be due to the fact that women do not arrive at menopause with equal risk of cognitive decline or equal susceptibility to the effects of HRT. We thus present a summary of current knowledge concerning the mechanisms of the neuroprotective action of estrogens and timing of hormonal exposure throughout the female life-cycle, and its probable effect on cognitive functioning. We then review studies undertaken to date on the cognitive effects of exogenous hormonal effectors, notably HRT, and finally suggest an integrative model of risk based on these findings to guide future research.

\section{MECHANISMS OF GONADAL HORMONE EFFECTS ON COGNITION}

\section{BRAIN TARGETS OF ESTROGEN ACTION}

Accumulating in vitro and in vivo evidence has indicated several potential brain targets of estrogens. Molecular mechanisms have been extensively reviewed [1-3] and can be summarized as follows. Two types of estrogen receptors (ER) have been identified (ER- $\alpha$ and ER- $\beta$ ) which mediate different functions. These receptors are encoded by two different genes located on separate chromosomes but sharing common structural features, with three principal domains - the amino-terminal or $\mathrm{A} / \mathrm{B}$ domain, the DNA-binding or $\mathrm{C}$ domain (showing more than $95 \%$ homology between $\alpha$ and $\beta$ ), and the ligand-binding or E domain (59\% homology). A fourth domain (F) is involved in distinguishing between estrogen agonists and antagonists. Like other members of the steroid receptor superfamily, ER are ligand-activated transcription factors. Estrogens can exert their effects using the "classical 
genomic delayed pathway" by binding to intracellular receptors that in turn lead to nuclear translocation, then induction of gene transcription and translation of proteins that can modulate neuronal survival in enhancing neurotrophic support, suppressing apoptosis or affecting neuronal structure. Estrogen can also act very rapidly through non genomic mechanisms interacting directly with various intracellular signaling pathways including mitogen activated protein kinase (MAPK), cAMP responsive-element binding protein (CREB), and phosphatidylinositol 3-kinase (PI3K), thereby affecting indirectly the transcription of several other target genes. Estrogen can activate selected intracellular signaling pathways depending on the receptor subtype bound. Another non-classical mode of estrogen action at the membrane has also been proposed involving the binding of estrogen to membrane-associated receptors, possibly at the caveolae level.

Both ER subtypes could be involved in estrogen neuroprotection, as suggested by the protection of hippocampal neurons by agonists for either $\mathrm{ER} \alpha$ or $\mathrm{ER} \beta$, against excitotoxic-induced damage and death [4]. Using $\mathrm{ER} \alpha$ and $\beta$ knockout mice, $\mathrm{ER} \alpha$, not $\mathrm{ER} \beta$, was shown to be required for the protective effects of estradiol against ischemia-induced injury [5]. On the other hand, the brains of ER $\beta$ knockout mice exhibited an increase in apoptotic cells in the ventricular zones of the cerebral cortex that resulted in abnormalities in brain development [6]. ER $\beta$ gene disruption was also found to impair optimal spatial learning in female mice, suggesting the role of ER $\beta$ in mediating learning and memory exerted by estradiol [7]

In the human forebrain, both ER subtypes are predominantly expressed in limbic-related areas, although they show distinct distribution patterns. The ER $\alpha$ mRNA expression appears to dominate in the hypothalamus and amygdala, indicating that the $\alpha$-subtype might modulate not only neuronal cell populations involved in autonomic and reproductive neuroendocrine functions but also areas implicated in emotional interpretation and processing. In contrast, the hippocampal formation, entorhinal cortex, and thalamus appear to be ER $\beta$ dominant areas, suggesting a putative role for ER $\beta$ in cognitive processing, declarative memory and motor functioning [1]. Little or no expression of ER $\beta$ is detected in reproductive tissues such as the uterus, where ER $\alpha$ has been shown to mediate the sexual characteristics of estrogen effects [8]. With minimal peripheral side effects, ER $\beta$ selective agonists could thus be designed to promote memory function and protection against neurodegeneration associated with $\mathrm{AD}$

\section{EVIDENCE FROM GENETIC STUDIES}

Several ER- $\alpha$ polymorphisms have been identified and linked to a variety of outcomes, including cognitive impairment and dementia, cardio-vascular pathologies, or modification of the effects of exogenous estrogen on 
lipid levels in older women. With regard to cognitive impairment and dementia, the ER- $\alpha$ IVS1-397 T/C (PvuII), IVS1-351 $\mathrm{A} / \mathrm{C}(\mathrm{Xba})$ in intron 1 , and the promoter region TA repeat polymorphisms have received the most attention. These same polymorphisms have also been implicated in cardiovascular pathologies together with IVS1$401 \mathrm{~T} / \mathrm{C}$ in intron 1, CA repeat, and a novel polymorphism in promoter B -1989 T/G (cf. [9]). The two polymorphisms most frequently associated with cognitive impairment and dementia are PvuII and XbaI: for most case control studies (including 83 to 223 cases), a significant increase in the frequence of these two polymorphisms was observed in patients with sporadic AD [10-13]. Only one study did not reveal any association [14]. Two studies have been carried out on Parkinson's disease with dementia: one (13 cases) showed an association with PvuII but not XbaI polymorphism [11], whereas the other (41 cases) showed no association with PvuII [15]. The only prospective cohort study of 2625 nondemented women over 65 years carried out to date also suggests an association between PvuII and XbaI polymorphisms and cognitive decline [16].

A significant interaction has also been observed between these two polymorphisms, PvuII or XbaI, and the apolipoprotein E $\varepsilon 4$ allele (ApoE-ع4) in the risk of developing familial AD (OR 11.3 compared to subjects without these genotypes and even higher for early onset OR 22) [17]. Such an interaction has also been found for late onset sporadic dementia, with an increase by 7.6-fold in homozygous ApoE- $\varepsilon 4$ inviduals with these ER $\alpha$ polymorphisms [10]. In a genetic study with 336 patients with $\mathrm{AD}$, it has been found that one particularly allele of the ER- $\beta$ gene (allele 5) could also act as a protective factor in $\mathrm{AD}(\mathrm{OR}=0.55)$ [18]. A potential interaction between these $\mathrm{ER} \alpha$ (PvuII and XbaI) and ER $\beta$ (3'UTR polymorphism/ AluI) polymorphisms and the risk of developing AD (71 men and 112 women included as cases) has also been reported [19] but in this case no independent association could be found. Hence, the existence of certain polymorphisms of ER could contribute to a significantly increased susceptibility of women to the beneficial (or harmful) effects of estrogens, a possibility which has not yet been explored thoroughly.

\section{STEROID EFFECTS ON NEUROTRANSMITTER SYSTEMS}

Estrogen can modulate neurotransmitter turn-over by several mechanisms, involving neurotransmitter synthesis, (re)uptake, release, receptor density, receptor interaction, enzymatic regulation, or gene expression. More specifically, estrogens can up-regulate cholinergic activity by induction of choline acetyltransferase and acetylcholine esterase in the basal forebrain, and increasing the high affinity choline uptake which is a regulatory rate limiting step in acetylcholine synthesis $[20,21]$.-Estrogen can also increase the rate of degradation of 
monoamine oxidase (MAO), which occurs in two isoforms, $\mathrm{A}$ and $\mathrm{B}$, and metabolizes catecholamines, e.g. serotonin (5-HT), dopamine (DA), noradrenaline (NA) with different substrate preferences [22]. In the macaque, one month of estrogen replacement alone decreased the expression of MAO-A, but not $\mathrm{B}$, in the raphe nucleus, whereas, in hypothalamic nuclei both MAO-A and B mRNA were decreased [23, 24]. In dorsal raphe, short- (1 month), but not long- (5 months) -term estrogen exposure decreases MAO-A protein expression, and progesterone supplementation was without effect. In contrast, MAO-B protein was unaffected by estrogen alone, but it was increased with short- or long-term progesterone supplementation [24]. The differential expression of the degrading enzymes in the presence of steroids suggests a complex combination of gene transcription, post-transcriptional processing, and substrate feedback mechanisms which may play a role in serotonin or catecholamine neurotransmission and hence, mood and cognition in humans.

In the midbrain serotonergic system, estrogen is implicated in the induction of tryptophan hydroxylase, and the regulation of 5-HT transporters and 5-HT receptor subtypes [24]. Estrogen regulates turnover of DA in hypothalamic nuclei and in nigrostriatal and mesolimbic DA systems and chronic estrogen administration decreases D1 and D2 receptor concentrations. Estrogen also facilitates amphetamine- or apomorphine-stimulated DA release. Systematic reviews of the effects of estrogen have concluded that estrogens enhance adrenergic activity by increasing tyrosine hydroxylase activity, facilitating NA release, and increasing galanin mRNA in some neurons which may affect noradrenergic tone by reducing NA reuptake. Furthermore, estrogen treatment transiently down-regulates GABA and Brain-Derived Neurotrophic Factor (BDNF) activity in inhibitory interneurons. Within the glutamate receptor family, N-methyl-D-aspartate (NMDA) receptors, AMPA receptors and kainite receptors (as well as sigma receptors) have also been demonstrated to be sensitive to steroid modulation [25].

Given the wide range of effects of steroid hormones on neurotransmitter systems, and also on neuronal organization and synaptogenesis, multiple neuroprotective effects could be expected on cognitive functions (notably attentional mechanisms, learning and memory), locomotor activity, pain sensitivity, and vulnerability to epilepsy (see for reviews $[22,26,27]$ ). Cognitive functioning and $\mathrm{AD}$ may be modulated through acetylcholine and its positive role on synaptogenesis in the hippocampus, which has a pivotal role in declarative memory [28, 29]. By modulating the activity of the cerebellum and the nigostrial and mesolimbic dopaminergic systems, estrogens have effects on normal and abnormal locomotor activity. High levels of estrogen exacerbate symptoms of Parkinson's disease, whereas low levels facilitate dopaminergic function. Finally, by modulating the sensitivity of D2-receptors in the brain, estrogens appear to have important neuroleptic-like effect [30] 
On the other hand, progesterone acts as a weak allosteric modulator of GABA's ability to increase chloride conductance through the $\mathrm{GABA}_{\mathrm{A}}$ receptor complex which confers on progesterone and its metabolites an action similar to that of benzodiazepines and barbiturates and may contribute to its anti-convulsant properties [31]. Progesterone and progestin compounds alone [32] or in combination with estrogens [33] are also capable of enhancing the DA system.

\section{OTHER NEUROPROTECTIVE EFFECTS OF ESTROGENS}

Estrogen has a neuroprotective effect on other specific mechanisms related to cognitive dysfunction, by blocking the action of neurotoxic agents or inhibiting their generation. It can notably protect cultured neurons against the neurotoxic effects of the excitatory neurotransmitter L-glutamate [34] or of the essential constituent of senile plaques in $\mathrm{AD}$, the amyloid $\beta(\mathrm{A} \beta)$ peptide, which is formed through the induction of oxidative stress [35]. The ability of $17 \beta$-estradiol to directly scavenge highly reactive free radicals, and thus shield neurons against exogenous oxidative insults and neuronal apoptosis, is due to the presence of the phenolic A ring [36].

The glial cells of the brain are targets for steroid hormones, and mediate different hormonal effects in the regulation of the development and plasticity of specific neuronal populations and in the control of endocrine events (see for review [2]). Glial cells express a number of proteins that can be regulated by estrogens including ApoE, which is implicated in membrane formation and structural plasticity, and glial fibrillary acidic protein whose expression increases with brain aging. Estrogens increase cerebral glucose utilization, possibly by inducing glucose transporter 1 in the endothelial cells of the blood-brain barrier, and thus regulate the ability of the brain to use glucose as its primary energy source. Neuroimaging studies have also demonstrated the role of estrogen in increasing both regional cerebral blood flow and glucose metabolism [37-39]. A recent review of neuroimaging studies concluded that estrogen replacement therapy (ERT) may decrease brain white matter lesions, have a modulatory effect on the various transmitter systems and alter regional brain activation patterns during cognitive processing [40], thus suggesting that estrogen may be implicated in functional plasticity in higher order brain functions. Finally, estrogens have been observed to reduce the acute phase of an inflammatory reaction and are also able to indirectly modulate lipoprotein levels, by decreasing the levels of LDL-cholesterol and increasing HDL-cholesterol, which could decrease the risk of atherosclerosis. This action has been hypothesized to confer a protective effect for both vascular dementia and $\mathrm{AD}$ as atherosclerosis has been implicated in both [41]. 
In summary, a plethora of in vitro and in vivo experimental data thus converge to support a positive role of estrogens on various neurotransmitter systems and on neuronal functioning. These various neuronal systems are notably involved in cognitive function, with global effects on attentional and mnesic functions, as well as more specific actions related to learning and remembering. Estrogens also appear to be implicated in various neurodegenerative disorders, notably the dementias, in which cholinergic, serotoninergic, dopaminergic, noradrenergic, and GABAergic systems are impaired. It would thus appear likely that estrogens could convey a benefic neuroprotective effect in relation to pathologies implicating cognitive dysfunction. This leads us to the question of whether endocrine fluctuations across the life-span, and not just one-off interventions with exogenous estrogenic modulators, may play a role in the onset of cognitive disorder and dementia.

\section{HORMONAL EXPOSURE ACROSS THE LIFE-SPAN AND EFFECTS ON COGNITIVE FUNCTIONING}

There has been a considerable body of research which has focused on the potential role of female gonadal hormones, especially estrogens, as possible modulators of susceptibility to the development and acceleration of cognitive pathologies. Fluctuations in gonadal hormones throughout reproductive life, from fetal life to old age, have often been shown to exert direct or potentiating effects on the central nervous system, giving rise in turn to both psychiatric disorders (notably depression) (Ancelin ML, Ritchie K, submitted for publication) and also, although less documented, to cognitive dysfunction. Hormonal status may also, at least in part, explain gender differences in vulnerability to various neuropsychiatric disorders.

\section{FETAL EXPOSURE AND EFFECTS ON NEURAL ORGANIZATION}

Ovarian steroids have multiple and complex effects on brain structure and functioning throughout life, beginning in utero, increasing dramatically at puberty and continuing on into senescence. The process of sexual differentiation of neuronal organization involves the secretion of testosterone and its conversion into estradiol via aromatase in fetal or early neonatal life, which largely determines the "defeminization" and "masculinization" of brain structures and function, for example by increasing neuronal density in the parietal and visual cortex. It has been observed for example, that during perinatal development, the hippocampus transiently expresses ERs, which coincide with the transient expression of aromatase. ERs in male would thus be exposed to locally generated estradiol which could lead to sexual differentiation of hippocampal structure and function. Estrogens affect areas of the brain that are not primarily involved in reproduction, such as the basal forebrain cholinergic system, 
hippocampus, cerebral cortex, caudate-putamen, midbrain raphe and brain stem locus coeruleus, and spinal cord (see for reviews $[22,26,27])$.

Estrogens have significant effects on the organization of developing neurons and activational effects on mature neurons. They can promote neurite growth and synapse formation and increase cholinergic neuronal survival. Estrogen regulates synaptic plasticity by stimulating axonal sprouting and dendritic spine formation in the hypothalamus and CA1 pyramidal neurons in the hippocampus, where de novo synapse formation involves the participation of glutamic acid, acting through NMDA receptors. Progesterone appears to have the opposite effect ; it can inhibit neurotransmission and lower brain excitability, which could notably lead to mood destabilization. Besides, it has a dismantling effect at the synaptic level. The adverse effect of progestins on cholinergic neuronal integrity as compared to ERT has also been demonstrated by Single Photon Emission Computed Tomography (SPECT) [42]. Estrogen regulates the morphology of astrocytes in the hypothalamus and hippocampus; such changes being perhaps indicative of glial cell activity in normal and lesion-induced synaptic plasticity. The co-localization of ER with neurotrophic factors (e.g. Nerve Growth Factor, NGF) and their receptors in basal forebrain cholinergic neurons could also favor interactions with these modulators of cell survival, and their co-regulation could promote neuronal survival, differentiation and plasticity (see for reviews [2, 3, 27].

Sex differences in brain structure and function are thought to occur as a result of differential exposure of men and women to sex hormones during fetal life [43]. This is suggested by studies of individuals with genetic disorders giving rise to abnormal levels of androgen exposure during fetal life. For example girls with congenital adrenal hyperplasia were found to perform better on tasks of spatial abilities (male-typical skills) and worse on tests of verbal abilities (female typical skills) compared to their unaffected sisters [44]. Girls with Turner syndrome, on the other hand, lack early androgen exposure and also show alteration of estrogen production due to abnormal ovarian function. They are characterized by a specific neurocognitive profile of normal verbal skills, impaired visual-spatial and visual-perceptual abilities, and impaired nonverbal relative to verbal memory. A recent randomized controlled trial (RCT) showed that 7-year-old girls with Turner Syndrome who were given two years of ERT showed improvement in verbal and nonverbal memory [45]. Adolescent girls with Turner syndrome treated for 2 years with androgen improved specifically in working memory, with no significant change in verbal abilities, spatial cognition, and executive functioning [46].

\section{PUBERTY AND ADULT DEVELOPMENT AND OBSERVED SEX DIFFERENCES IN COGNITIVE FUNCTIONING}

Fluctuating hormone levels associated with the menstrual cycle have been shown to modify cognitive 
performance in women, however, there is presently no consensus on the nature of these changes (which could be rather small in magnitude) and their possible correlation with seric hormonal levels. Studies vary with regard to the cognitive tests used and target subjects, but generally indicate that when estradiol levels are highest, i.e. during the late follicular (proliferative) phase or at the midluteal phase, motor and verbal ability are seen to improve, with lowering of perceptual-spatial performance compared to levels achieved during menstruation when ovarian hormone levels are lowest (Table 1). Lack of consensus may be attributable to a number of factors which have not been adequately controlled for, including mood, which is also known to fluctuate during the cycle, thus constituting a potential confounder. There is also inconsistency in definitions of menstrual cycle phase and many women (especially younger women) have an anovulatory cycle with a hormone profile which is different from the ovulatory cycle [47]

In adults gender differences in cognitive functioning have been extensively reviewed [48-53]. Although no single study has adequately defined gender differences, conclusions from multiple studies suggest that females, on average, score higher on verbal abilities, notably on tasks that require rapid access to and use of phonological and semantic information in long-term memory, production and comprehension of complex prose, and also on fine motor skills, perceptual speed and accuracy. Males, on average, score higher in spatial and quantitative abilities, notably on tasks that require transformations in visuo-spatial working memory, motor skills involved in aiming, spatio-temporal responding, and fluid reasoning. Overall, while scores on most cognitive tests show normal distributions in both men and women, the female curve tends to be higher at the mean with smaller standard deviations (kurtosis). Thus while males more frequently have high scores on cognitive tasks, they are also overrepresented in the low-ability end of several distributions, including mental retardation, attention disorders, dyslexia, stuttering, and delayed speech. However, the effects although consistently found, are modest (0.5-1 SD) and are not reflected in full-scale IQ scores.

Aging of the normal brain is accompanied by changes in brain structure, metabolism and function which may differ by sex [54]. Overall, for both sexes, normal brain aging has been associated with a decrease in motor speed and increase in reaction time as well as alterations in divided attention, visuospatial and learning abilities. On the other hand, semantic memory and language abilities appear to remain relatively stable or may even improve in the absence of other pathologies [55]. Cognitive performance is seen to decline overall with age in both sexes, however, between-gender comparisons of the slope for age on each cognitive function test after adjustment for education, depressed mood, and estrogen use (in women) indicate that men have a significantly steeper decrement 
with age than women for total recall and long-term memory, on immediate and delayed visual recall, and category fluency [56]. These results are compatible with other studies showing that women retain an advantage over men in verbal function well into old age [55, 57].

\section{MENOPAUSE AND COGNITIVE FUNCTIONING}

In perimenopause, memory changes and concentration difficulties are commonly reported and short-term memory loss is considered a common cognitive change during the menopausal transition, although a direct causal link with hormonal changes has not been established [58]. Very few studies have attempted to objectively measure such cognitive changes by neuropsychological tests, reports of memory and attentional difficulties being based for the most part on subjective self report. In a population-based cross-sectional study of 362 women aged 52 to 63 years, no significant difference in episodic verbal memory (assessed by word list learning) was observed during the menopausal transition or in the years immediately after [59]. On the other hand, women who began HRT during the menopausal transition had better memory scores (immediate recall) than women who began estrogen after the final menstrual period which could indicate that there might be a critical window during which HRT must be initiated to protect memory as has been reported by Resnick et al. for visual memory [60] and Zandi et al. for AD [61]. The absence of a premenopausal comparison group, and the possibility that women with memory complaints may preferentially be prescribed HRT, could have limited this study. To date, only one population-based longitudinal study [62] has followed the cognitive performance of women as they progress through the menopausal transition. Progression from premenopause to perimenopause through a natural menopausal transition, was not associated in this study of 803 women with a significant decline in working memory or perceptual speed, although difficulties were observed at the late perimenopausal and postmenopausal phases. This study was, however, limited by uncertainty as to the actual timing of the transition and the nature of the cognitive assessment: only two brief measures of cognitive performance were used, without any evaluation of verbal memory (the cognitive function most likely to be altered due to estrogen depletion), and without taking into account learning effects (especially given that learning effects might decrease during the menopausal transition).

The type of menopause which leads to distinct estrogen depletion may also determine type of cognitive dysfunction. The symptoms associated with surgical menopause are possibly more severe as there is a more abrupt depletion of estrogens and endogenous androgens than in natural menopause, where the ovaries continue to produce small amounts of estrogen. Compared to women with natural menopause, women with surgical menopause 
are at greater risk for cardiovascular disorder, osteoporosis, and depression (see for review [63]). Women who have undergone oophorectomy have also been shown to have lower scores on some post-operative measures of cognitive functioning, i.e. verbal short-term memory, long-term memory and logical reasoning, whereas patients who had a hysterectomy, but whose ovaries were retained, showed stability in cognitive performance [64]. Napi et al. also reported that surgical menopause affected specifically short-term verbal memory more than physiological menopause (with no significant difference on attention and psychomotor tasks), with performances correlating both to the age at the time of ovariectomy and to the years since surgery; higher scores being related to older age at surgery [65]. Concentration and attention difficulties have also been reported for unnatural menopause in women treated with adjuvant cancer chemotherapy, although treatment also induced hot flushes which may also be associated with such difficulties [66].

\section{AGEING-RELATED COGNITIVE DISORDER AND DEMENTIA}

At least $10 \%$ of persons over 65 years old and $50 \%$ of those over 85 have some form of cognitive impairment ranging from mild deficits to dementia [67]. AD constitutes the most frequent form of dementia which accounts for about $70 \%$ of all dementias, followed by Lewy Body dementia (20\%), vascular dementia (15\%) and dementia of the Parkinson type (5\%). Prevalence of $\mathrm{AD}$ is around $4 \%$ increasing logistically from $2 \%$ at age 65 to reach an asymptote at 80 years with an estimated prevalence of $20 \%$ [68]. This non-Gaussian increase in prevalence suggests that $\mathrm{AD}$ is not simply a normal involutional process, but that biological factors other than those implicated in brain ageing are involved. Moreover, age-related changes in the prevalence curve are not the same in men and women. Women are overall more at risk of developing dementia than men, and the prevalence of $\mathrm{AD}$ is higher in women than in men after the age of 65-70 years, by 2-3-fold. This gender difference persists even after correcting for differences in life expectancy [69-71]. The meta-analysis performed by Gao et al. [72] reported a significantly higher incidence of $\mathrm{AD}$ in women compared to men, correcting for increased female longevity $(\mathrm{OR}=$ 1.56). Edland et al. [73] have suggested that sex difference in AD incidence could be related to geographical differences; a higher incidence for women being observed in European and Asian populations, but not in the US.

In age-related neurodegenerative processes such as $\mathrm{AD}$, the earliest reported symptom is commonly inability to learn and recall new information followed by a progressive loss of other cognitive abilities. Attention, concentration and some verbal skills (notably word-finding) are also affected at an early stage whereas major spatial disorientation, serious language disorders (absent from normal aging), apraxia and agnosia usually occur at 
a later stage [74]. There is some limited evidence to suggest that the pattern of cognitive loss is not the same in men and women, and that women have an earlier onset and faster progression (see for review [2]). During the course of $\mathrm{AD}$, women tend to show greater impairments in language skills, especially naming and word recognition, delayed recall, semantic memory, and possibly also verbal fluency [75-77]. Bayles et al. found no significant difference between the performance scores of male and female subjects with $\mathrm{AD}$, only reporting relatively small effect sizes of gender, with female patients outperforming males on language tests [78].

\section{ENDOCRINE FLUCTUATIONS AND COGNITIVE FUNCTIONING: A CONTINUUM MODEL}

The marked cyclic fluctuations in estrogen and progesterone that occur as part of the reproductive cycle, or due to other extrinsic causes, appear to play an important role in enhancing susceptibility to cognitive dysfunction or neurological disorder, as well as substantially influencing clinical course and symptom severity. Similar symptoms are reported by women complaining of premenstrual syndrome, premenstrual dysphoric disorder, postpartum depression or postpartum psychosis, and the perimenopausal transition and menopause; all of which occur at a moment when estrogen level decreases and/or when there is a relative or absolute lack of progesterone or progestins, although no correlation has been demonstrated with seric levels. These symptoms notably include mood swings and a decreased sense of well-being, irritability, anxiety, memory and cognitive dysfunction. These disorders associated with reproductive-cycle transitions in women are often closely related; women with a history of mood disorder associated with reproductive events (e.g. premenstrual and puerperium disorders) appear to have an increased risk of depression at perimenopause (see for reviews [79-81]). With regard to depression, a model has thus begun to emerge which conceptualizes the brain estrogen minimum set point in women as a continuum starting with a premenstrual syndrome in the $20 \mathrm{~s}$, and encompassing postpartum depression in the $30 \mathrm{~s}$, followed by the cyclic symptoms of the perimenopausal 40s and ending with the menopause syndrome itself. This hypothesis of a continuum of vulnerability has received little attention in relation to cognitive disorders.

In summary, adult females tend to perform better on tasks of verbal memory and fine motor coordination compared to males, whereas males perform better on perceptual-spatial tasks. However, whenever estrogen levels in women are decreased, whether during fetal life (related to genetic disorders), or during the menstrual phase, or after the menopause, this pattern may be inversed; low levels of estrogen favouring typically male skills and being detrimental to typically female skills. Such a pattern may be reversed, at least partly or temporally, by exogenous 
administration of estrogen which could modulate cognitive function, notably verbal memory (exemplified by the effects of ERT on girls with Turner Syndrome, of the contraceptive pill on non-menopausal women, and the possible although controversial, effects of ERT on menopausal women, see below). Hence, it is increasingly evident, at least for some women biologically vulnerable to normal changes in reproductive hormones, that whenever brain estrogen levels fall below the minimum brain estrogen requirement, for whatever reason and at whatever age, brain dysfunction may ensue, leading to various neuro-psychiatric disorders.

\section{EXOGENOUS HORMONAL EFFECTORS AND COGNITION}

Various clinical studies have investigated the effects of exogenous estrogens or substitutive treatment on cognitive function, as well as on the risk and course of dementia. Most epidemiological studies of hormonal intervention have focused on the menopause when hormonal deprivation is the most dramatic and definitive, and during which some women appear particularly vulnerable to health changes.

\section{THE WORLD-WIDE DIVERSITY OF HRT}

Rozenberg et al. have reviewed the various HRT formulations and their use in Europe compared to the U.S. [82]. A much larger choice of products and administration modes characterizes the European in comparison with the US market. European women may use a variety of estrogens, whereas in the US, about $90 \%$ of postmenopausal women use oral conjugated equine estrogens (CEE), which mainly contain estrone sulfate (26 metabolites have been reported for Premarin, one of the most frequently used CEE). Systemic estrogens may be given orally, transdermally, intradermally, vaginally, or by injection. A nasal spray is also now available in European countries. In Europe, dermal pathways predominate in the South (France, Italy, Spain) whereas oral formulations prevail in Anglo-Saxon countries. The older European products contained estradiol valerate, and the more recent ones micronized $17 \beta$-estradiol. These products are more widely publicized and used in European countries than the CEE, which are also available in Europe. In the U.K., CEE predominate (as in the U.S.) whereas $17 \beta$-estradiol is the most prescribed compound in France. Weak estrogens, which do not protect against osteoporosis but relieve women from climacteric symptoms, such as estriol, were very popular until recently in some European countries.

The current consensus is that women who have not undergone hysterectomy should be prescribed an opposed treatment with added progestagen. The same diversity as for estrogens is also found for progestagens, which can be divided into three subgroups: the C-21 derivatives of progesterone (medroxyprogesterone acetate - 
MPA-, dydrogesterone), C-19 derivatives of nortestosterone (norethisterone) and natural progesterone and similar compounds [82]. In the U.S, MPA is the most used progestagen (which is mostly used in combination with Premarin). In Europe, norethisterone acetate, natural micronized progesterone, medrogeston, cyproterone acetate, lynestrenol, norgestrel, and dydrogesterone are often used. In France, progesterone or its natural isomer, dydrogesterone and synthetic derivatives (pregnanes or norpregnanes) are preferred and in U.K., the use of acetate of norethisterone, levonorgestrel and MPA predominates. Progestagens are mostly given orally, but transdermal systems (norethisterone acetate, levonorgestrel) are also used in the Scandinavian countries.

Tibolone, a hybrid molecule with estrogenic, progestogenic and androgenic properties, is also popular in some European countries. This product has mainly been used to relieve symptoms and avoid withdrawal bleeding. Its action in relation to osteoporosis prevention has been recognized in some countries, and its effect on cardiovascular function is still a subject of research and debate. Raloxifene, which is not a conventional HRT but a selective estrogen receptor modulator (SERM), has been available in Europe since 1999 [83].

As a result of this heterogeneity and the wide array of products available, Europe lacks large long-term RCT which use the same products across countries to estimate the risk and benefit of HRT on health outcomes, such as cognitive function, psychiatric symptomatology, cardiovascular diseases, and breast cancer [82]. In the U.S., The Women's Health Initiative Study (WHIS) involving the follow-up of 8300 women, and the Women's International Study of long Duration Oestrogen after Menopause (WISDOM, 2240 women) in the U.K., Australia and New Zealand, due to be completed in 2005 and 2006 respectively, were designed to provide information about the

effects of HRT. The Preventing Postmenopausal Memory Loss and Alzheimer's disease with Replacement Estrogens study (PREPARE in the U.S.) will specifically address the question of whether estrogens can delay or prevent dementia [84]. The HRT which is evaluated in all these studies, is continuous oral administration of CEE with or without MPA. At the present time, both trials of opposed and unopposed estrogen in the WHIS had to be prematurely discontinued due to an accumulation of risks over benefits (see below). On the basis principally of the WHIS findings, the WISDOM Study has also been terminated. In Canada, the Estrogen Memory Study currently underway is evaluating the effectiveness of a safer formulation, using oral administration of $1 \mathrm{mg} 17 \beta$-estradiol (continuous) and $0.35 \mathrm{mg}$ norethindrone (cyclophasic), in improving memory in postmenopausal women who may be at a higher risk for $\mathrm{AD}$ (63 postmenopausal women with memory problems, in both arms).

\section{EFFECT OF HRT ON NORMAL COGNITIVE FUNCTIONING}

The effect of HRT on cognitive functioning in non-demented menopausal women has been evaluated in 12 
retrospective or cross-sectional studies, 16 prospective studies and $17 \mathrm{RCT}$. No detrimental effect has been observed in any of these studies except in one small cross-sectional study in which surgically menopausal women were treated with an estradiol implant about 10 years before [85]. Eighteen pairs were matched for age, IQ, education level, socio-economic status, and occupation. ERT users had poorer mental flexibility (rule reversal) and long-term episodic memory than the control group; the difference was small but significant even after accounting for the increase in depression and somatic symptoms in ERT users $(\mathrm{p}<0.05)$. There were no differences in a test of sustained attention or in a category generation task. The great majority of observational studies actually suggest a positive effect of HRT on cognitive functioning, but benefits might globally be small and rather inconsistent, implicating only some specific cognitive functions (see below). The absence of a marked beneficial effects in women with asymptomatic menopause compared to symptomatic women initially led to the hypothesis that cognitive improvement was more likely to be a result of improved quality of life due to the resolution of menopausal symptoms (vasomotor symptoms and depressive symptomatology), "the domino effect", rather than from a direct effect of estrogens on cognitive functioning. There is, however, now some evidence in support of a possible direct positive effect of HRT on cognitive functioning even in asymptomatic postmenopausal women [86, 87] so that it is possible that both direct and indirect effects may interact.

Among the cognitive functions so far examined, verbal learning and memory have been extensively studied using different research designs. The results suggest there may be improvement in verbal performance, notably verbal memory, however, studies are not unanimous (see for reviews [53, 88-91]). Visual memory has not been systematically explored, and the few studies conducted to date have given contradictory results showing either no effect [86, 92-94], some improvement with ERT [60, 95, 96] or decline which could be reversed after supplementation with dienogest, suggesting an antagonistic effect of progestin [97]. The beneficial effect on visual memory, if any, is small compared to the possible effect on verbal memory and may only be evidenced in larger samples using a wide range of neuropsychological tests. A recent review of cross-sectional and longitudinal Positron Emission Tomography (PET) studies of HRT recipients revealed a between group difference in patterns of regional brain activation evoked during performance of delayed verbal and figural memory tasks, as well as greater relative blood flow increases over two years in the hippocampus and other mesial temporal lobe structures that subserve memory [98].

Several shortcomings in cognitive assessment have been reviewed by Rice and Morse, notably with regard to attention and concentration, which have not been systematically examined. They also stressed that tests of visual 
memory assume intact visuo-spatial discrimination, but this point is rarely considered. They recommend the simultaneous examination of verbal and visual memory, concept formation and reasoning [91]. Despite the difficulties inherent in the quantitative summation of studies with widely variable study designs, a meta-analysis has nonetheless been undertaken by Hogervorst [89]. The results were drawn from the nine more robust studies over the first 15 RCT carried out before 2001. They suggest improvement with estradiol only (but probably not Premarin, whether or not associated with a progestagen) on tests of immediate verbal memory recall, verbal reasoning and motor speed and accuracy, with no consistent effects on other verbal functions, visual or visuospatial recall, working memory, divided attention, mental tracking, or mental status. These very specific effects were essentially observed in relatively young surgically menopausal women who had been given a monthly intramuscular injection of $10 \mathrm{mg}$ estradiol for 3 months [89]. A reduction in ER expression or in cholinergic function after sustained estrogen level has been reported [21,99] which could explain why only early and transient positive effects could be evidenced. Nevertheless, results of the meta-analysis were unable to specify whether duration, formulation, dose, or progestin could alter cognitive performance to a clinically significant level.

The results of the largest ongoing RCT of hormone therapy, The Women's Health Initiative Memory Study (WHIMS) were published just after the publication of the meta-analysis of Hogervorst et al. The study has used only a brief global measure of cognitive function (the modified MMSE) in postmenopausal women aged 65 years or older, free of probable dementia at baseline [100]. In the first arm of this study, which was terminated early because of unacceptable side effects (increased risk of breast cancer, heart disease, stroke and pulmonary embolism [101], 4532 women received daily oral $0.625 \mathrm{mg}$ of CEE plus $2.5 \mathrm{mg}$ of MPA (continuous administration) or placebo. The 3MSE mean total scores in both groups increased slightly over time (mean follow-up of 4.2 years) due to a learning effect. Estrogen plus progestin did not improve global cognitive function when compared with placebo (mean differences in 3MSE scores between HRT users and placebo was -0.18 units, $\mathrm{p}=0.055$ ). There was only a small increase in the proportion of women showing a clinically meaningful cognitive decline (of 2 SD) in the estrogen plus progestin group (6.7\%) compared to the placebo group (4.8\%). Very recently, the second arm (2808 hysterectomized women receiving daily oral $0.625 \mathrm{mg}$ of CEE or placebo) has also been abolished due to excess of stroke and an absence of benefit for the primary cardiovascular outcomes [102]. During a mean follow-up of 5.4 years, mean 3MSE scores were 0.26 units lower among women assigned to CEE compared with placebo in analyses without covariate adjustment $(\mathrm{p}=0.04)$ [103]. For women assigned to CEE compared with placebo, the relative risk of having a 10-unit decrease in $3 \mathrm{MSE}$ scores (>2 SD) was estimated to be $1.47\left(\mathrm{CI}_{95} 1.04-2.07\right)$. The 
adverse effect of hormone therapy was more pronounced among women with lower cognitive function at baseline $(\mathrm{p}<0.01)$. When women who developed cognitive impairment or dementia were excluded, the mean difference was moderated and no longer statistically significant. In fact, the actual magnitude of the differences in $3 \mathrm{MSE}$ scores between the treated and placebo group is too small to have relevance in clinical practice. It is important to note, however, that the 3MSE is a brief evaluation of global cognitive function designed exclusively to screen for dementia in elderly subjects; it cannot be considered as a cognitive battery, it is inappropriate for use in this population with a wide age range, is inadequate for detecting change across time, and is subject to ceiling effects in non-dementing subjects. It is also invalid to consider an item equivalent to a specific cognitive test. The detailed effect on individual cognitive tasks is expected to be published later.

\section{HRT AND DEMENTIA}

\section{Preventive effect on Alzheimer's disease: observation studies}

Sixteen observational studies have been published between 1984 and 2002 to evaluate the preventive effect of HRT on the risk of developing post-menopausal dementia. Seven case-control studies did not indicate a significant effect: two (the oldest studies) showed a non-significant increased risk of dementia among HRT users compared to non-users $[104,105]$, three showed no difference [106-108] and two found a non-significant decreased risk of dementia among users compared to nonusers $[109,110]$. On the other hand, nine studies indicated a significant protective effect of HRT: five case-control studies [111-115] showing a 48 to $67 \%$ reduction in risk of developing $\mathrm{AD}$, a cross-sectional study [116] showing $76 \%$ of risk reduction and the cohort studies, indicating a 41 to $69 \%$ reduction in the risk of developing $\mathrm{AD}[61,117,118]$. Regarding possible dose effects, only one study reported a necessary minimum daily dose of $1.25 \mathrm{mg}$ CEE [109], whereas Waring et al. found no such effect [112]. It is unclear if a critical duration of HRT is necessary to have a protective effect. Different studies indicate positive effects after 6 months, one, three, seven, or ten years $[61,111,112,118]$. This wide range observed for optimal treatment duration is probably mainly related to the timing of the treatment. Zandi et al. reported recently that prior HRT use was associated with reduced risk of $\mathrm{AD}$ (the strength of the association increasing with the duration of the past treatment), but without any apparent benefit with current HRT use unless such use exceeded 10 years [61].

In the past five years, four meta-analyses have been performed from the above studies, concluding that there is a $29 \%$ [119], 34\% [88], 38\% [90] and 44\% [120], reduction in the risk of developing dementia in the group of ever users of estrogen, compared to never users. In all cases, the authors emphasize the presence of possible biases 
and lack of control for potential confounders such as education, depressive symptomatology and ApoE genotype, inadequate information regarding the effects of progestin use, the estrogen preparations, dose or duration of therapy. The effects of these possible methodological limitations were notably highlighted by the difference in OR observed when comparing the results of the studies carried out before 1994, i.e. less robust, with less subjects, and with less rigorous statistical analysis ( $\mathrm{OR}=1.08$ not significant and showing high heterogeneity) with that performed after $1994(\mathrm{OR}=0.49$, significant and very low heterogeneity) [120].

\section{Preventive effect on Alzheimer's disease: The specificities of the WHIMS RCT}

The recent results of the WHIMS which was carried out in community-dwelling women aged 65 to 79 years, are not consistent with the findings of mechanistic and observation studies. The WHIMS design involved a 4.2 year daily oral administration of CEE $(0.625 \mathrm{mg})$ plus MPA $(2.5 \mathrm{mg})$, which was observed to lead to a two-fold increase of the risk for probable dementia (all dementia types) in 2947 postmenopausal women (HR 2.05, $\mathrm{CI}_{95}$ 1.21-3.48). No significant difference in $\mathrm{AD}$ risk was found for either the treatment or placebo arms of the study [121]. The significant effect in this study was related exclusively to vascular dementia, which was increased in the treatment $\operatorname{arm}(12.5 \%, \mathrm{n}=5$ vs. $4.8 \%, \mathrm{n}=1$ in the placebo group). The number of women with a history of cardiovascular disease was higher in the treatment than in the placebo arm, a factor which is likely to have significantly affected the outcome (see also below). In 4532 hysterectomized women, a 5.2 year daily administration of CEE alone $(0.625 \mathrm{mg})$ did not significantly modify the risk for probable dementia (all types) compared to the placebo group (HR 1.49, $\mathrm{CI}_{95}$ 0.83-2.66) [122]. In this trial, the proportion of women with vascular, $\mathrm{AD}$ or mixed dementia was lower than in the placebo group. Pooling data for both trials (CEE alone and CEE + MPA), the overall HR for probable dementia was $1.76\left(\mathrm{CI}_{95} 1.19-2.60\right)$. HRT effects on mild cognitive impairment did not significantly differ between groups whether the women were treated with CEE + MPA (HR 1.07, $\mathrm{CI}_{95}$ 0.74-1.55) or with CEE alone (HR 1.34, $\mathrm{CI}_{95}$ 0.95-1.89) or after pooling the data ( $\mathrm{HR} 1.25, \mathrm{CI}_{95}$ 0.97-1.60) [121, 122].

The validity of combining the two analyses, CEE alone with CEE+MPA (as was specified in the original protocol) could be questioned, as besides having undergone surgical menopause, women in the CEE arm also had lower mean education and family incomes, lower baseline 3MSE scores, weighed more, consumed less alcohol, and had more cardiovascular disease, hypertension, diabetes, and vasomotor symptoms. Although the numbers are small, the incidence of dementia and MCI is $33 \%$ higher in hysterectomized women than in those with a uterus, regardless of treatment with HRT or placebo. It should also be mentioned that about $45 \%$ of the women in the 
CEE-alone WHIMS trial had previously taken HRT vs. $31 \%$ in the CEE+MPA group. Prior use of HRT appeared to slightly reduce the risk for probable dementia although not significantly ( $\mathrm{HR} 0.87, \mathrm{CI}_{95}$ 0.32-2.39), compared to $1.95\left(\mathrm{CI}_{95}\right.$ 0.94-4.04) for never users. All these considerations should have been taken into account when comparing or pooling the two WHIMS interventions. Further analyses estimating each woman postmenopausal exposure to endogenous and exogenous estrogens, in terms of years since menopause or hysterectomy are required, however, the number of women in each category may be too small to obtain reliable estimates.

In conclusion, the discrepancies between the WHIMS and other studies may be attributed to a number of factors. Firstly, with regard to the patient group: in the WHIMS, women were older than 65, far from the perimenopause period and thus very different from the usual clinical situation in which HRT is prescribed around menopause. They were also less healthy, with cardiovascular risk at randomization, with an excess of hypertension, obesity, and tobacco use [101]. The high dropout rate in WHI (42\% in the HRT group and $38 \%$ in the placebo group), the more frequent unblinding in the HRT group than in the placebo group, the type of formulation (oral CEE and MPA, which is probably the combination of a weak neuroprotective estrogen with an ineffective, if not antagonistic, progestin, see below) as well as the doses used (which can be considered as high for a first-line treatment in older postmenopausal women) are also causes of concern [123].

The increase in the risk of developing dementia in the CEE + MPA group (but not in the CEE group) may be due primarily to an increase in vascular risk. This is also consistent with the $31 \%$ increase in ischemic stroke already reported in the WHI study after 5.6 years of CEE + MPA treatment [124]) and the high and rapid increase in deep venous thrombosis, which increased by 3.6-fold after only one year of treatment [125]. Silent cerebral infarcts and micro-vascular changes in deep white matter are now recognized to be important risk factors for vascular and also $\mathrm{AD}$ type dementias [126]. The vascular risk hypothesis is also supported by observations that adverse effects such as venous thrombosis, coronary heart disease or stroke, occur very early in treatment, often in the first year [125].

Altogether, the WHIMS results do not prove that HRT has no effect on AD, but they clearly indicate that women older than 65 years should not be treated with CEE with or without MPA to attempt to prevent dementia or enhance cognition. The WHIMS design was unsuitable for the investigation of a neuroprotective effect, and it is hardly surprising that no protective effect was found. Furthermore, the results of the WHIMS could also not be extrapolated to other countries, especially Europe where other HRT using natural steroid hormones (e.g. estradriol 
and progesterone) and other modes of administration (transdermal $v$ s. oral mode) are preferred. These differences in clinical practice may be related to less harmful effects (see below) and urgently merit further investigation.

\section{Effect of HRT on the severity of Alzheimer's disease}

The effects of HRT on women with AD have been evaluated in eight therapeutic trials (including five RCT). They have been unable to demonstrate a clear beneficial effect of estrogen therapy on AD severity. More particularly, the three most recent controlled, double-blind therapeutic trials, conducted by Henderson et al., [127], Mulnard et al [128] and Wang [129] observed neither a statistically significant benefit of CEE for any of the individual cognitive or functional assessments, nor a decrease in the severity of dementia after a year of treatment. In a smaller RCT with 20 postmenopausal women with $\mathrm{AD}$, Asthana et al. reported improvement in attention and some verbal, visual and semantic memory tasks in women using a skin patch of $17 \beta$-estradiol $(0.1 \mathrm{mg} /$ day $)$ for 8 weeks, compared to women receiving placebo [130]. This effect was independent of the hormone effect on mood. After several weeks of treatment withdrawal, the improvement was no longer evident. In a recent meta-analysis of five RCTs including 210 women with $\mathrm{AD}$, Hogervorst et al. could only demonstrate a short term (2 months) positive treatment effect of transdermal estradiol (but not of CEE) on verbal memory (on cued delayed recall of a word list) but not on visual memory, language functions, most speeded tests, clinical rating scales or depression. They also reported a very limited positive effect from low dosage of CEE $(0.625 \mathrm{mg} /$ day $)$ but not from higher dosage $(1.25 \mathrm{mg})$ on the global MMSE score only after 2 months but not after 3,6 and 12 months of treatment. Whether age, dementia onset or the use of a particular preparation for a longer duration of treatment could have different effects remains speculative [131].

Few studies have investigated the enhancing effect of HRT associated with drugs used in the treatment of AD. In a RCT with 118 women of at least 50 years of age, of whom 13\% were taking ERT (mainly CEE) over a mean period of 11 years, enhancement of the efficacy of the anticholinesterasic agent, tacrine, in the treatment of cognitive function in dementia was observed after 30-weeks [132, 133]. By contrast, a recent RCT found no beneficial effect of HRT (transdermal estradiol $0.025 \mathrm{mg} /$ day + oral progesterone $100 \mathrm{mg} /$ day) when coadministered with rivastigmine for 28 weeks to 59 elderly menopausal women (mean age 76 years, mean menopause duration 26 years) [134]. The difference in age, time elapsed since menopause as well as treatment type (unopposed $v s$. opposed) could probably explain the observed discrepancies between the two studies. It should also 
be noted that the effect of cholinesterase treatment for $\mathrm{AD}$ has been reported to vary for women (but not for men) according to their ApoE $\varepsilon 4$ status; women with an $\varepsilon 4$ allele having less of a treatment effect [135].

Thus, whereas some studies suggest that estrogen may act as a preventive agent for neurodegeneration, there is presently no evidence that this hormone acts as a restorative agent in already degenerated neural tissue, although such a hypothesis is credible (cf. $[60,61]$ ). Experimental data also supports these findings, indicating that estrogen could be neuroprotective when administered before or at the same time as the neurodegenerative stimulus, but not when administered afterwards (see for reviews $[2,136]$ ).

\section{STUDY LIMITATIONS AND VARIABILITY AS THE PRINCIPAL CAUSE OF INCONSISTENCIES IN RESULTS}

\section{Epidemiological studies and cognitive evaluation}

Most therapeutic trials conducted to date have been unable to conclude that HRT could significantly prevent the development of AD or decrease its severity. Epidemiological studies, especially the earlier ones (before 1994), have numerous limitations (see for reviews $[91,119,120]$ ). Variability in the neuropsychological tests used and their limited range as well as the lack of standardized diagnostic criteria for dementia are among the principal shortcomings making difficult any comparison between studies. There are numerous other factors which are potential confounders which have not been systematically controlled for; most studies showing a high heterogeneity with regard to subjects (age, education level, ...). More specifically, depressive symptomatology is an important confounding variable, which has rarely been evaluated. ApoE- $\varepsilon 4$ status is also rarely given although it is an important genetic risk factor for $\mathrm{AD}$, and an interaction has also reported with ERT status [137]. Although current longitudinal studies are better controlled and more robust, randomization precludes the identification of other potential confounders. In prospective cohort studies on HRT, there is also specific bias. The HRT users are preferentially healthy, non depressed, with a high level of education and higher socioeconomic status; in themselves protective factors against cognitive decline (healthy user bias). Another source of bias is that women with memory complaints may have been preferentially prescribed HRT (bias by indication). Loss of subjects is also a cause of concern in longitudinal studies. In a recent review, Sherwin et al. reported that in about half of all longitudinal studies, the 25 to $30 \%$ of women who failed to return for cognitive testing were older, have less education, had lower MMSE scores at baseline, and were more likely to be non-users [53]. Clinical therapeutic trials with no control group raise the problem of learning effects which are frequent after repetitive cognitive evaluation with the same tests. RCT are the most robust studies (although generally of small size and short term) 
but the validity of the double-blind is open to question: women frequently guess the type of treatment they received, due to bleeding or menopause symptom resolution. Greendale et al. reported that when women were asked at the end of a 3-year protocol, $60 \%$ of the placebo group guessed the type of treatment they received, compared to $85-90 \%$ in the group who received HRT [138].

\section{Menopause, HRT formulations and biological oucomes}

Other design problems are related to the heterogeneity of subjects included in HRT studies with regard to age and health, varying definitions of menopausal status (including or not premenopausal women), and the type of menopause, natural or surgical, the latter giving perhaps more consistent results due to the sudden and complete loss of estrogen across subjects (see for reviews [84, 120, 139]). HRT timing is also problematic: the mean duration of an RCT is usually less than 6 months (the longest trial being WHIMS which lasted 5.2 years) whereas the average duration of observation studies is 13 years, and the time between the exposure window and the menopause age, which is probably critical for a beneficial cognitive effect, is highly variable (observation studies being closer to the real clinical situation than RCT where HRT is not administered during the early menopause transition). There are also numerous differences with regard to type of HRT (the more recent large RCT only used oral CEE with continuous MPA, whereas natural steroid hormones are probably more beneficial, due in particular to their distinct pharmacokinetic properties) [140], or in the sequence of administration of progestin (women with estrogen and cyclic progestin treatment were shown to be significantly less likely to report cognitive symptoms such as concentration than when administered with an opposed continuous treatment [141], as well as for estrogen (continuous administration being susceptible to reduce ER concentration by autoregulation [142]). Lastly, there is also variability in the preparations used (oral vs. patch, the parenteral mode short-cutting first-pass liver effects), which can result in various pharmacokinetic patterns. The transdermal administration of estradiol is reported to provide a rapid rise in estradiol serum level and nearly constant levels (i.e. constant estradiol-estrone ratios) over the entire application period. Oral administration, on the other hand, results in highly variable serum levels of estradiol, and lower bioavailability compared with estrone whose plasmatic accumulation could be 3-fold higher than after estradiol transdermal administration (and 20-fold higher in the mammalian gland) [143].

Distinct biological effects of HRT formulation have already been reported in relation to breast cancer or cardiovascular outcomes, notably due to variable metabolization. Transdermal estradiol is less harmful on markers of cardiovascular risk than oral estradiol (or CEE) which activates blood coagulation, increases C Reactive Protein 
(CRP) and modifies other biological markers such as triglyceride or LDL level, or also LDL particle size [144148]. This was also recently suggested by a multicentre hospital-based case-control study which showed that oral but not transdermal ERT was associated with a 4-fold increase in risk of venous thromboembolism in current users [149]. Moreover, the harmful effect of progestins, especially synthetic derivatives (e.g. MPA) has been reported for cardiovascular risk $[150,151]$. Regarding breast cancer, MPA + oral ERT was reported to increase mitotic activity in epithelial cells in postmenopausal breast [152] whereas this mitotic activity was decreased when progesterone was added to transdermal ERT [153]. The recent data of the Million Women Study in the UK indicated an increased risk with estrogen-progestagen compared to estrogen only, with very little variation between specific estrogens and progestagens [154], but it should be mentioned that the complete history of hormonal treatment was not considered in this study, which only focused on the most recent treatment taken. On the other hand, the first French prospective study in which $83 \%$ of the 3175 postmenopausal women were receiving a combination of a transdermal estradiol gel and a progestin other than MPA did not show any evidence of increase in breast cancer risk even after 9 years of treatment [155] whereas an increase in breast cancer was observed early after treatment with CEE + MPA (RR 1.26, $\mathrm{CI}_{95}$ (1.00-1.59) afer a mean follow-up of 5.2 years) [125]).

The addition of progestin may have had a modifying effect on the risk of developing dementia because progestins, especially MPA, have been reported to attenuate or counteract the effects of estrogen and possibly increase the risk of thromboembolic events [156], or cardiovascular disease [157]. With regard to neuroprotective effects, there is also accumulating evidence for a different effect between MPA and other progestins. Progesterone has been reported in vitro to be neuroprotective alone or when administered with estradiol (although to a lesser degree than estradiol alone) whereas MPA was an ineffective neuroprotectant and even completely antagonized estrogen-induced neuroprotection when co-administered $[158,159]$. This is also suggested by a prospective observational study in which women taking CEE + MPA scored significantly lower in global cognitive functioning, abstract reasoning and verbal fluency than both never users and ERT only users after a 2-yr treatment [160]. Hence, there are several lines of evidence to suggest that HRT prescribed in the U.S. (oral CEE and MPA) could be less neuroprotective (or more harmful) than that prescribed in Europe and especially in France (transdermal estradiol and natural progesterone) regarding various clinical outcomes (see for review [161]). All of these points have undoubtedly to be taken into account before drawing any definitive conclusion regarding the effects of HRT on cognitive functioning and dementia. 


\section{EFFECTS OF OTHER ESTROGENIC MODULATORS ON COGNITIVE DISORDERS}

Many estrogen-related diseases, including breast cancer, and polycistic ovarian syndrome, endometrial cancer and endometriosis are treated with drugs possessing antiestrogenic activity, which may also elicit most of the same symptoms as those commonly shared by women with low estrogen exposure [79]. There has thus been some concern that antiestrogen treatment for breast cancer prevention may be associated with cognitive dysfunction. Synthetic, nonhormonal compounds, SERM, have been developed that could have estrogen agonist and antagonist actions in estrogen-responsive tissues. The two most widely recognized SERM, tamoxifen and raloxifene, have estrogen-agonist properties on bone and lipids and estrogen-antagonist effects on breast, whereas raloxifene unlike tamoxifen, has estrogen-antagonist effects on the uterus [162]. Their effects on brain have been reviewed leading to the conclusion that tamoxifen may antagonize some of the beneficial effects of estrogen on the CNS (it notably acts as a pure estradiol antagonist with respect to serotonergic mechanisms), whereas raloxifen may exert estrogen-like effects on cholinergic transmission [163]. The anti-ER effect is also supported by the fact that women with breast cancer treated with tamoxifen commonly report vasomotor symptoms, mood instability, and cognitive dysfunction

In a study aimed at comparing cognitive functioning in 1163 women (aged 57-75), little difference between women who had used tamoxifen for five years and never users were reported on three cognitive tests (clock drawing, copying a box drawing and narrative writing) [164]. Current users had a significantly lower mean complexity score only on the narrative writing task, indicating that current use of tamoxifen may adversely effect certain cognitive functions in a reversible way since there was no difference between past users and non-users. Current users also reported more frequently consulting their physicians for memory problems than nonusers. Using a battery of neuropsychological tests, van Dam et al. reported a dose-dependent deleterious effect on cognitive function in women who have received standard or high doses of adjuvant chemotherapy plus tamoxifen compared to controls, but in the absence of a tamoxifen arm (without adjuvant chemotherapy) one cannot conclude that there is a specific effect with tamoxifen [165]. Another cross-sectional study failed to detect any significant deleterious effects on cognitive functioning. Tamoxifen may in fact have deleterious effects on cognitive function specifically at the beginning of therapy and if high dosages are used (see for review [163]).

With regard to raloxifene, an RCT with 143 postmenopausal women reported no consistent effect on cognitive functioning using a battery of computerized tests, nor on mood, compared to placebo over one year [166]. The large trial of raloxifene in 7,478 osteoporotic postmenopausal women was completed over three years (the 
Multiple Outcomes of Raloxifene Evaluation [MORE] trial). On the six cognitive tests performed, mean cognitive scores improved slightly over the three years. Compared to the placebo group, women assigned to raloxifene had a slightly lower risk of developing cognitive decline on attention and verbal memory tests only [167]. Improvement in verbal memory with raloxifene has also been reported in two smaller studies, one including postmenopausal women without $\mathrm{AD}$ and the other postmenopausal women with $\mathrm{AD}[168]$.

Hence tamoxifen may have estrogen-antagonist effects on the brain, whereas raloxifen may have estrogenagonist properties. These data require confirmation by well-designed longitudinal studies, taking into account the methodological limitations in most previous studies. For example, the relative contributions of adjuvant chemotherapy, adjuvant hormonal therapy (i.e. SERM by itself) and chemotherapy-induced menopause remain to be explored as well as other confounding factors related to female susceptibility (i.e. age, education, depressive symptomatology...) [163]. A large American and Canadian study, the Co-STAR study (Study of Tamoxifen And Raloxifen/cognition) is currently investigating the effects of tamoxifen and raloxifen on cognition in 2000 women aged 65 years or over and with high breast cancer risk.

Finally, gonadotropin releasing hormone $(\mathrm{GnRH})$ agonists which are used to treat benign chronic gynecological disorders such as endometriosis and uterine fibroids or myoma, or premenstrual syndrome, suppress ovarian function and thus have hypo-estrogenic side effects, vasomotor symptoms, mood disorders, and bone demineralization. Temporary cognitive decline has also been reported. As an example, the GnRH agonist, leuprolide acetate depot $(3.75 \mathrm{mg}$, intramuscularly, every week), was shown to decrease verbal memory and learning (but not visual memory) after 12 weeks of therapy in young, healthy women, compared to pretreatment baseline when their ovaries functioned normally. Mood scores also increased during the ovarian suppression phase, but this was not clinically significant and did not influence cognitive scores significantly. This memory deficit could be prevented (as were the symptoms of hypoestrogenism) by concurrent "add-back" estrogen administration (CEE $0.625 \mathrm{mg}$ for 8 weeks) [169]. This suggests that estrogen may help to maintain verbal memory in women and that, at least in the short term, cognitive changes due to estrogen deprivation could be reversible with ERT provided the delay between cognitive symptom onset and treatment is not too long.

In summary, whereas a neuroprotective role for estrogen might be expected, this has not as yet been adequately demonstrated. Comparing cognitive performance across or between conditions associated with different hormone exposure, such as phases of the menstrual cycle, (surgical) menopause and various exogenous hormonal 
effectors, including ERT, SERM or GnRH agonists, suggests a possible effect at least on verbal memory, but this has not been conclusively demonstrated. On the other hand, it is still uncertain as to whether there is a preventive effect on dementia in spite of the numerous studies already performed. One probable short-coming has been the focus on late-onset (menopausal) hormonal changes i.e. at a time when the neurodegenerative process has already begun, and without taking into account individual life-time exposure to hormonal variability. Many of the inconsistencies reported in the literature may be due to the fact that women do not arrive at menopause with equal risk of cognitive decline, or equal susceptibility to the effects of HRT. There is now some evidence to suggest the existence of vulnerable female subgroups at high risk of developing neuro-psychiatric disorders at specific moments in their reproductive life, e.g. when a drastic drop in estrogens occurs, such as at the premenstrual phase of the cycle, after postpartum, or at the perimenopause period. While the identification of this subset of hormonesensitive subjects would permit the preventive use of a tailored therapy based on steroid hormones, the key hormonal determinants of risk of cognitive impairment and psychiatric disorder, still remain to be characterized.

\section{PHYSIOLOGICAL MARKERS ASSOCIATED WITH LIFELONG CUMULATIVE ESTROGEN EXPOSURE}

\section{SERUM HORMONAL LEVELS AND GENDER DIFFERENCES}

Understanding of the peripheral metabolism of precursor steroids in the main estrogen target tissues appears fundamental to ascertaining the mechanisms underlying the development of diseases associated with the decline in circulating estrogen levels after menopause. Although the ovaries are the principal source of systemic estrogen in the premenopausal non-pregnant woman, other sites of estrogen biosynthesis are present throughout the body: the mesenchymal cells of adipose tissue and skin, osteoblasts and perhaps chondrocytes in bone, vascular endothelial and aortic smooth muscle cells, as well as several sites in the brain, including the medial hypothalamus, the amygdale and the hippocampus. In men and postmenopausal women, the estrogen synthesized within these extragonadal compartments probably has no major role as a circulating hormone, but is rather only biologically active at a local tissue level in a paracrine or intracrine fashion (see for review [170]).

Extragonadal estrogen synthesis involves the enzymatic transformation, by aromatase, of androgens which become the principal source of estrogens after menopause. Compared with women, men maintain a high circulating level of active precursor testosterone throughout life (10-30 $\mathrm{nM} v s .0-5 \mathrm{nM}$ in women), which is available for aromatisation, in extragonadal sites. Because the levels of circulating testosterone in the male are similar to the $\mathrm{K}_{\mathrm{m}}$ of aromatase (20-30 nM), it is likely that circulating testosterone in men can be converted efficiently in 
extragonadal sites to produce sufficiently high local concentrations of estradiol sufficient for transactivation of ER (both $\alpha$ and $\beta, \mathrm{Kd}$ around $1 \mathrm{nM}$ ) whereas in women the conversion to estradiol would be less efficient. The level of circulating testosterone in men is also 2-3 orders of magnitude greater than the mean level of circulating estradiol in postmenopausal women $(30-70 \mathrm{pM})$ and in men $(25-130 \mathrm{pM})$ (see for review [170]). Given that much of the circulating estradiol is bound to sex hormone-binding globulin, it is unlikely to have a major impact on transactivation of the ER, compared with estrogen produced locally as a consequence of aromatisation of circulating testosterone. Thus, the uninterrupted sufficiency of circulating testosterone in men throughout life supports the significant local production of estradiol by testosterone aromatization, and could probably afford ongoing protection against estrogen deficiency related diseases. Aromatization is probably important in terms of protecting the bones of men against mineral loss [171], and might also contribute to the maintenance of cognitive function and prevention of $\mathrm{AD}$ in men.

Several factors must be thus taken into account when considering the physiology of estrogen levels. In general, ovarian steroids are concentrated several-fold in brain relative to plasma, and the turnover rate of brain sequestration of blood-borne sex steroids is high compared with other steroids such as corticosteroids [26]. Due to the difference in kinetic diffusion rates across the blood brain barrier for estrogen, progesterone and testosterone, the presence of localized brain neurosteroids and aromatase, and the possible variations in progesterone receptor dimerization, blood tests and serum level evaluation are generally not very helpful or informative [79].

\section{SERUM HORMONAL LEVELS AND COGNITIVE DISORDERS}

Within this context it might be expected that research aiming to establish a correlation between seric endogenous hormonal levels and disease with a gender specific pattern would be inconclusive and controversial. Whereas some studies conducted in elderly women have shown positive relationships between high endogenous serum levels of estrogens (and testosterone) to some verbal memory functions and negative relationships to visuospatial functions, other studies have not found any relationships with cognitive performance (Table 2). More recently, Hogervorst et al. reported that high levels of total estradiol had a positive relationship with verbal memory in women, but not in men, whereas total testosterone had a negative relation to verbal recall especially in women. On the other hand, some other verbal (paired associates, graded naming) and visuospatial tasks (paired associates, recognition) showed no relationships with hormone levels. Hence, not all cognitive functions could be improved with higher levels of sex steroids and such effects seemed to be modified by sex; the sex-sensitive tests showing the 
clearest effects with possible interaction of age with levels of sex hormones [172].

Possible associations of seric hormonal levels with dementia have also been investigated. Senanarong et al. reported, that lower estradiol levels were correlated with poor cognitive, behavioral, neuropsychiatric symptoms and functional status in 135 community-based older men and women of whom 72 had dementia and 63 did not [173]. They defined a threshold level of endogenous estradiol in the elderly for the risk of developing dementia being less than $15 \mathrm{pg} / \mathrm{ml}(<55 \mathrm{pM})$ in men and less than $1 \mathrm{pg} / \mathrm{ml}$ in women [173]. This threshold varies somewhat from that reported by Manly et al. who found that the risk for AD in postmenopausal women was increased 4-fold for estradiol levels less than $20 \mathrm{pg} / \mathrm{ml}$ [174], with no significant association with estrone serum levels.

In a recent $\mathrm{RCT}$ carried out with 120 hysterectomized postmenopausal women with $\mathrm{AD}$, no association was found between estradiol or estrone levels and neuropsychological test scores on 7 different assessments at baseline compared to 2 or 12 months follow-up [175]. Geerlings et al. also could not find any association between higher levels of endogenous total or bioavailable estradiol and reduced risk of dementia in 584 women or 493 men [176]. No significant differences in estradiol levels were found in a further small study of $21 \mathrm{AD}$ and 12 healthy women [177]. Hogervorst et al. found no difference in female testosterone levels between cases of AD and controls. By contrast, men with $\mathrm{AD}$ had significantly lower levels of testosterone, which could indicate that low testosterone may be a co-morbid feature of $\mathrm{AD}$ in men, or that low testosterone levels could exacerbate the disease [178].

Finally, Hogersvorst et al. pointed out that the sensitivity of the assay could determine the reported value of the estradiol levels [179]. They carried out a meta-analysis to assess whether the sensitivity of the assays of past studies had affected the reported level of total estradiol, and also measured total estradiol in 66 women with AD and 62 controls. Two assays were used to assess the difference between sensitive (radioimmunoassay with a specific rabbit antibody, $3 \mathrm{pM}$ ) and relatively insensitive (immunoassay, $37 \mathrm{pM}$ ) assays. The meta-analysis of nine studies indicated that insensitive assays gave higher levels of total estradiol when a large number of samples fall below the level of insensivity of the method. This might explain earlier reports of low levels of total estradiol in $\mathrm{AD}$, since total estradiol levels (using the sensitive assay) in controls were one third of those reported in the earlier studies. Using the sensitive assay they found that women with AD had significantly higher levels $(26 \pm 13 \mathrm{pM})$ of total estradiol than controls $(21 \pm 13 \mathrm{pM})$. Using the insensitive assay, there was no significant difference in the levels of total estradiol. The sensitivity of the assay could thus have determined the previously reported value of the estradiol levels. Studies using a sensitive assay do not report significantly lower levels of total estradiol in women with $\mathrm{AD}$, which argues against the hypothesis that low levels of total estradiol are a risk factor for $\mathrm{AD}$. At the 
present time, the reasons for estradiol increase in $\mathrm{AD}$ remain unclear, one explanation being ER polymorphic variability in $\mathrm{AD}$ cases

The association between steroid hormone level and cognitive functioning thus remains controversial and at the present time it is still uncertain as to which steroid serum level is the better predictor (estradiol, estrone, testosterone...), under which form (total or non-protein-bound and bioavailable), whether this could be specific for only some cognitive functions and time points and even the direction of the association (increase or decrease). The link with serum gonadotropins (e.g. luteinizing hormones (LH), and follicle stimulating hormones (FSH) which are sensitive to changes in estrogen and the primary regulator of estrogen production) also remains to be clarified [180, 181]. Whether a seric threshold could be defined for any of these steroids, whether this threshold is distinct for men and women or whether optimal levels of steroids are needed to maintain brain function with no therapeutic value for ERT once $\mathrm{AD}$ is present are some of the questions which remain unanswered. Interestingly, the absence of an association with postmenopausal estrogen levels has also been reported with other pathologies such as osteoporosis and vertebral fractures, for which the protective effect of estrogen is nevertheless well documented [182]. For breast cancer, the data available from prospective studies of estradiol level among premenopausal women are also inconclusive whereas for postmenopausal women a positive association was shown between serum estradiol concentrations and risks (see for review [183]). Direct determination of serum estrogen levels, especially in the premenopause period, may thus not represent the best means of detecting relative estrogen deficiency, as serum levels fluctuate and the level of any single estrogen may not always reflect the total integrated end-organ effects of multiple circulating compounds possessing estrogenic properties [184]. More clinically useful measures of endogenous estrogenic effects at the level of specific tissues (notably brain) must be sought, for instance using PET scans in combination with biomarkers.

\section{PHYSIOLOGICAL MARKERS ASSOCIATED WITH LIFELONG ESTROGEN FLUCTUATION}

Apart from cyclic variations in serum hormonal levels during reproductive life, various clinical markers are candidate indicators of lifelong endocrine fluctuations. Earlier age at menarche ( $<11$ years $)$ which favors a higher than average estradiol serum level for 10 to 30 years after menarche, nulliparity and late first pregnancy (after 30 ), and late menopause (after 55) are among the physiological factors associated with an increased exposure to estrogens. Conversely a later age at menarche, pregnancy and longer time since menopause result in decreased exposure to estrogens. Obesity during the climacteric is also a key factor associated with an increase in estrogen 
exposure. After the menopause, mesenchymal cells of adipose tissue become the main source of estrogen via testosterone aromatization. Therefore, in the post-reproductive years, the extent of female estrogenization is mainly determined by adiposity. This is of clinical importance considering that corpulent women are relatively protected against $\mathrm{AD}$ [185] and osteoporosis [186] but more at risk of estrogen dependent breast cancer [187].

Pregnancy is associated with specific variations. Serum estrogens (estrone, estradiol and estriol) and progesterone levels are increased very quickly during pregnancy, while smoking during pregnancy lower the maternal estriol levels by $20 \%$ or more throughout pregnancy. After parturition, serum estrogen levels are dramatically decreased but at sufficient levels to continue to stimulate prolactine liberation for 2 days. During lactation, estradiol levels are as low as at postmenopause (see for review [188]).

Regarding exogenous endocrine effectors, use of OCs and postmenopausal ERT (whose dosage is generally lower than OCs), their time and duration of use are exogenous factors also contributing to modify estrogens levels, whose effects could be further modulated in case of combination with progestins. By contrast, a decreased exposure to estrogens could result from various events, including castration (after surgery, chemotherapy or radiation), or exposure to various compounds possessing antiestrogenic activity, such as tamoxifen (or other SERM), progestins, antiandrogens, (which could be used for treatment of hormonal dependent cancers), GnRH agonists (used in benign chronic gynecological disorders or for the treatment of sterility) or diethylstilbestrol DES (which has been used in the past to avoid miscarriage during pregnancy).

The search for consistent associations between endogenous estrogen levels and cognitive function has been inconclusive. An interesting alternative is bone mineral density (BMD), which is a potential surrogate marker for endogenous estrogen. Bone contains ER, and BMD is positively correlated both with endogenous and exogenous estrogens and could thus be considered a marker for lifelong estrogen exposure. BMD is also an associated factor in various hormone-dependant pathologies. For example, high BMD has been shown to be a marker for risk of breast cancer [189-192], whereas women with higher bone mass, have a decreased risk of colon cancer [193], probably reflecting greater cumulative estrogen exposure. BMD was also reported to be a marker of cumulative estrogen exposure associated with cognitive function in non-demented older women. Yaffe et al. have shown that women with osteoporosis, whether measured by baseline $\mathrm{BMD}$, reductions in $\mathrm{BMD}$, or vertebral fractures, have poorer cognitive function and greater risk of cognitive deterioration [194]. BMD was also shown to be associated with verbal memory impairment (delayed recall) among 4,304 elderly subjects in the Third National Health and Nutrition Examination Survey [195]. More recently, Lui et al. [196] observed that women with more rapid hipbone 
loss were more likely to develop global cognitive decline - defined as a decline of 3 or more points on repeat mMMSE score - (after a mean follow up of 4.5 years of 4462 women older than 70 ) than those who had lower rate of loss (or who gained bone mass), an association which could not be explained by known suspected risk factors for bone loss and cognitive decline. Women with dementia are also at higher risk of fracture of the femur.

In summary, the association between hormonal serum level and cognitive functioning remains controversial. Gobal marker(s) of cumulative estrogen exposure should be explored as possible indirect measures of base-line hormonal status, to be used as co-variates in establishing associations with cognitive and neuro-psychiatric disorders, rather than more "instantaneous" or local markers such as serum hormonal levels.

\section{TOWARDS AN INTEGRATIVE MODEL OF CUMULATIVE ESTROGEN EXPOSURE}

The decrease or increase of estrogen associated with specific markers has been associated with the risk of developing hormone-dependent conditions, including osteoporosis and certain cancers, in which the notions of cumulative hormonal exposure and hormonal windows have been largely used [197-200]. The study of reproductive and menstrual factors on risk for hormone-sensitive cancer has increasingly relied on mathematical models that combine multiple markers into a single equation [201-203] as such indices provide greater predictive power than consideration of individual markers [204]. For breast cancer, the well-established reproductive risk factors are early age at menarche, nulliparity, late age at first full term pregnancy, late age at any birth, low parity among parous women and late age at menopause. Regarding exogenous hormonal effectors, such as OCs, an increased risk was observed, especially for women continuing treatment close to the menopause (see for review [183]). In relation to HRT, a recent meta-analysis reported an increased risk of 1.35 for 5 years of use or more [203]. This notion has also been widely used for BMD, a higher bone density being associated with a longer endogenous (e.g. early menarche, parity, and late menopause) or exogenous hormonal exposure: HRT prevents the menopausal decrease in bone density and thus decreases the risk of hip fracture, whereas premenopausal use of OCs, also affects bone loss and reduces the risk of hip fracture [205-208]. This bone protective effect increases with OC dose and probably also with duration of administration; better protection being observed in older women, i.e. those who were the closest to menopause [208].

While the utility of global clinical markers of estrogen exposure has been established in breast cancer and osteoporosis, little work has been done to determine if they are useful in understanding the effects of estrogens on 
brain functioning. This methodology has only just begun to be applied in the area of cerebral functioning to examine cognitive disorder in the elderly, but this research is limited with regard both to the cognitive functions selected and the estrogen markers studied. Smith et al. reported for 87 elderly nondemented women that an index, combining menstrual, reproductive, and physical markers associated with estrogen levels (e.g. body mass index), was related to better performance on two verbal tasks [209]. No individual marker showed a pattern of associations with cognitive performance as consistent as did this combined index, indicating that the effects of estrogen on brain may be more apparent when the cumulative effects of exposure are evaluated [209]. This also suggests some interplay between long-term structural changes and short-term activational mechanisms. Nappi et al. also reported that early surgical menopause was associated with poorer cognitive function (in short term verbal memory but not in attention tasks) in a study with 103 young patients [65]. In a longitudinal study including 361 post-menopausal women, nulliparity and late menopause were associated with significantly less cognitive decline at follow up as measured by changes in MMSE, which suggests that a higher lifetime, natural exposure to estrogen is associated with less age-related cognitive decline [210]. Others possible markers that could influence hormonal function such as age at menarche, number of total pregnancies (resulting or not in live births), lactation, have not been explored in this study. Alternatively, Richards et al. have investigated the association between cognitive function at ages 8,11 , 15,26 , and 43 years and timing of the menopause using a Cox proportional hazard models in 1572 women from the British 1946 birth cohort. Higher cognitive scores were shown to be associated with later menopause (with the strongest effect in childhood cognitive performance) [211]. Cognitive testing will be repeated in this study at age 53 years, so that it will be possible to determine whether women who come early to menopause are at greater risk for cognitive decline, suggesting that causal factors could be in place long before the onset of the climacteric. Such long term prospective studies provide a more appropriate means of evaluating the possible associations of cognitive dysfunction with life time estrogen exposure, than retrospective studies which are subject to memory bias with regard to self report of markers of lifetime exposure.

The association between life-time hormonal exposure and $\mathrm{AD}$ has received less attention than the relationship with sub-clinical cognitive dysfunction. An association between parity and AD has been reported in 106 women with a diagnosis of AD compared to 189 control women without dementia [212]. Studies of the association of increased risk of $\mathrm{AD}$ with advanced age at menarche and advanced age at menopause are inconclusive, one study showing a positive association with age of menarche but not with age of menopause [109], another showing the opposite [116], whereas other studies found no effect for either factor [112, 118]. An earlier 
onset of menopause was found in women at risk of dementia, i.e. with a positive family history of disease, but this was not found in those without a family history of dementia [213]. However, it is not clear whether early menopause is the cause or the consequence of the AD pathology. Another study of 3601 women aged 55 years and over, using as markers only age at menarche and menopause, found a significant increase in risk of dementia in women with natural menopause and more reproductive years and who were also ApoE $\varepsilon 4$ carriers. No such association was observed in non-carriers [214].

In summary, numerous studies suggest that a combined index reflecting lifetime cumulative estrogen exposure, may constitute a more significant determinant of cognitive functioning in the elderly than a single marker (such as ERT). Hence, the characterisitics of the reproductive period merit further examination as potential markers of long-term exposure to endogenous estrogen. However, the studies conducted to date have focused on only a small number of reproductive life events (generally age at menopause or/and age at menarche) without considering other endogenous factors (such as menstrual cycle history, total pregnancies, lactation) and exogenous factors such as OCs or antiestrogen effectors (as is the case in hormone sensitive cancer or endometriosis) have been neglected.

\section{CONCLUSION AND FUTURE DIRECTIONS}

A plethora of strong in vitro and in vivo experimental evidence converge to support a positive role of estrogens on various neurotransmitter systems and on neuronal functioning. The estrogen influence on cognitive functioning is also suggested by gender differences in cognitive performance (females performing better on tasks of verbal memory and fine motor coordination and males performing better on perceptual-spatial tasks). Comparing performance across or between conditions associated with different hormonal exposures, such as phases of the menstrual cycle, (surgical) menopause and various exogenous hormonal effectors also suggests a possible effect at least on verbal memory, but this was not firmly demonstrated, the effects being sometimes modest or with limited clinical relevance. The search for consistent associations between endogenous estrogen levels and cognitive function has been inconclusive, but it should be mentioned that measurement of endogenous estrogen is technically difficult, and it is unclear how serum levels may reflect local brain estrogen concentrations or how well a single measurement is correlated with cumulative estrogen exposure.

On the other hand, it is still unclear as to whether estrogen has a preventive effect on dementia in spite of the numerous studies performed. Whereas most observational studies conducted in the 10 last years (i.e. the most 
robust ones) consistently indicated a 41-76\% decreased risk of developing AD among HRT users, the recent results of the WHIMS did not show any significant effect after 5.2 years of CEE treatment and even indicated a two-fold increase in dementia (essentially vascular dementia, but not $\mathrm{AD}$ ) after 4.2 years of treatment of CEE+MPA. Current therapeutic trials are unsuitable for the detection of neuroprotective effects of HRT, considering the populations studied (women aged 65 years and older, very far from the menopause and thus from the usual clinical situation), and the duration, dose, and type of HRT (oral CEE and MPA) whose neuroprotective properties have never been recognized and whose side-effects (especially cardiovascular) could be extensive. This is quite different from observation studies in which women begin HRT younger, at the perimenopausal period, and using (especially in Europe) natural steroids whose pharmacodynamic properties are probably more favorable.

One key short-coming has probably been the focus on late-onset (postmenopausal) hormonal changes i.e. at a time when the neurodegenerative process has already begun and without taking into account individual life-time exposure to hormonal variability. There is now some compelling evidence to suggest that combining the effects of clinical, reproductive, and menstrual events within a cumulative exposure model integrating all the characteristics of the reproductive period as well as exogenous hormonal effectors, may provide a more useful approach to the understanding of the effects of steroids on the brain. Further research is needed regarding the possible differential effects on risk of cognitive dysfunction, of endogenous $v s$. exogenous and short $v s$. long-term effects of estrogen, especially at the critical period of the perimenopausal transition. Analyses providing both detailed reproductive histories and adequate longitudinal data on cognitive decline are lacking. Multifactorial models based on an exhaustive view of all the hormonal events throughout the reproductive life should be explored more thoroughly to isolate the key hormonal determinants of cognitive disorders in the elderly. This could also lead to the identification of vulnerable sub-groups of hormone-sensitive women, who may be at high risk of developing cognitive symptoms (on the basis of their lifetime endocrine pattern). This would open up the possibility of offering tailored therapies based on steroid hormones. The public health consequences of such a preventive programe would be considerable bearing in mind the projected increases in $\mathrm{AD}$ prevalence (14 million people worldwide may be suffering with $\mathrm{AD}$ by the middle of the $21^{\text {st }}$ century [215]) and also the increase in menopausal women (who presently constitute around $15 \%$ of the western population) due to population aging. In the U.S., Henderson has predicted that should a neuroprotective effect of ERT be established, its widespread use during menopause could reduce the number of women with $\mathrm{AD}$ by more than one million [216]. At a more general level, Brookmeyer et al. have estimated that delaying disease onset by only two years, could permit a decrease in $\mathrm{AD}$ prevalence by at least $20 \%$ [217]. 
Women do not arrive at menopause with equal risk of cognitive decline or equal susceptibility to the effects of HRT. The reason why some women seem more vulnerable to neuropsychiatric disorders remains poorly understood and a multifactorial approach incorporating other predisposing factors (environmental, genetic, or biological, e.g. vascular factors) is required. At the present time there is little data to support these hypotheses and further studies should focus on the integration of adequate information on reproductive history. Geerlings et al. reported that the risk of dementia appeared more pronounced in Apoc4 women with higher reproductive years (calculated as the difference of age of menopause minus age at menarche), whereas in non carriers no clear association was observed [214]. In yet another study, estrogen use was associated with less cognitive decline among $\varepsilon 4$-negative women but not $\varepsilon 4$-positive women. Potential mechanisms, including carotid atherosclerosis, by which $\varepsilon 4$ may interact with estrogen and cognition have been evoked and also warrant further investigation [137]. The existence of several polymorphisms of ER ( $\alpha$ or $\beta$ ) could also contribute to a distinct susceptibility of women to the beneficial (or harmful) effects of estrogens; a possibility which has not yet been adequately explored.

Future research will also involve the development of new SERM and studies of their interaction with ER subtypes. The "ideal" SERM which is still actively being sought, should provide the benefits of estrogen with regard to postmenopausal health but with minimal risks; that is maintaining bone density and serum lipids, without increasing the risk of breast or endometrial cancer, and without the side effects associated with current SERM (e.g. venous thromboembolism and hot flushes). It could thus provide protection against menopausal symptoms, osteoporosis, cardiovascular disease, hormone dependent cancer, and also cognitive function. The present review has suggested a number of directions for future clinical research. Large trials are now required to explore these hypotheses within a multifactorial model which takes into account reproductive history and genetic predisposition including ER polymorphisms. In the future it may also be useful to extend such a cumulative risk model beyond cognitive factors to include psychiatric disorders. 


\section{REFERENCES}

[1] Osterlund, M.K., Hurd, Y.L. Estrogen receptors in the human forebrain and the relation to neuropsychiatric disorders. Prog Neurobiol, 2001, 64, 251-67.

[2] Garcia-Segura, L.M., Azcoitia, I., DonCarlos, L.L. Neuroprotection by estradiol. Prog Neurobiol, 2001, 63, 29-60.

[3] Behl, C. Oestrogen as a neuroprotective hormone. Nat Rev Neurosci, 2002, 3, 433-42

[4] Zhao, L., Wu, T.W., Brinton, R.D. Estrogen receptor subtypes alpha and beta contribute to neuroprotection and increased Bcl-2 expression in primary hippocampal neurons. Brain Res, 2004, 1010, 22-34.

[5] Dubal, D.B., Zhu, H., Yu, J., Rau, S.W., Shughrue, P.J., Merchenthaler, I., et al. Estrogen receptor alpha, not beta, is a critical link in estradiol-mediated protection against brain injury. Proc Natl Acad Sci US A, 2001, 98, 1952-7. Epub 2001 Feb 6.

[6] Wang, L., Andersson, S., Warner, M., Gustafsson, J.A. Estrogen receptor (ER)beta knockout mice reveal a role for ERbeta in migration of cortical neurons in the developing brain. Proc Natl Acad Sci US A, 2003, 100, 703-8. Epub 2003 Jan 6.

[7] Rissman, E.F., Heck, A.L., Leonard, J.E., Shupnik, M.A., Gustafsson, J.A. Disruption of estrogen receptor beta gene impairs spatial learning in female mice. Proc Natl Acad Sci U S A, 2002, 99, 3996-4001. Epub 2002 Mar 12.

[8] Shughrue, P.J., Lane, M.V., Merchenthaler, I. Comparative distribution of estrogen receptor-alpha and beta mRNA in the rat central nervous system. J Comp Neurol, 1997, 388, 507-25.

[9] Herrington, D.M., Howard, T.D., Hawkins, G.A., Reboussin, D.M., Xu, J., Zheng, S.L., et al. Estrogenreceptor polymorphisms and effects of estrogen replacement on high-density lipoprotein cholesterol in women with coronary disease. $N$ Engl J Med, 2002, 346, 967-74

[10] Brandi, M.L., Becherini, L., Gennari, L., Racchi, M., Bianchetti, A., Nacmias, B., et al. Association of the estrogen receptor alpha gene polymorphisms with sporadic Alzheimer's disease. Biochem Biophys Res Commun, 1999, 265, 335-8.

[11] Isoe-Wada, K., Maeda, M., Yong, J., Adachi, Y., Harada, H., Urakami, K., et al. Positive association between an estrogen receptor gene polymorphism and Parkinson's disease with dementia. Eur $J$ Neurol, $1999,6,431-5$.

[12] Ji, Y., Urakami, K., Wada-Isoe, K., Adachi, Y., Nakashima, K. Estrogen receptor gene polymorphisms in patients with Alzheimer's disease, vascular dementia and alcohol-associated dementia. Dement Geriatr Cogn Disord, 2000, 11, 119-22.

[13] Urakami, K., Wakutani, Y., Wada-Isoe, K., Yamagata, K., Adachi, Y., Nakashima, K. [Causative genes in Alzheimer's disease]. Nippon Ronen Igakkai Zasshi, 2001, 38, 117-20.

[14] Maruyama, H., Toji, H., Harrington, C.R., Sasaki, K., Izumi, Y., Ohnuma, T., et al. Lack of an association of estrogen receptor alpha gene polymorphisms and transcriptional activity with Alzheimer disease. Arch Neurol, 2000, 57, 236-40.

[15] Mattila, K.M., Rinne, J.O., Roytta, M., Laippala, P., Lehtimaki, T., Urakami, K., et al. Lack of association between an estrogen receptor 1 gene polymorphism and Parkinson's disease with dementia. Acta Neurol Scand, 2002, 106, 128-30

[16] Yaffe, K., Lui, L.Y., Grady, D., Stone, K., Morin, P. Estrogen receptor 1 polymorphisms and risk of cognitive impairment in older women. Biol Psychiatry, 2002, 51, 677-82.

[17] Mattila, K.M., Axelman, K., Rinne, J.O., Blomberg, M., Lehtimaki, T., Laippala, P., et al. Interaction between estrogen receptor 1 and the epsilon 4 allele of apolipoprotein $\mathrm{E}$ increases the risk of familial Alzheimer's disease in women. Neurosci Lett, 2000, 282, 45-8.

[18] Forsell, C., Enmark, E., Axelman, K., Blomberg, M., Wahlund, L.O., Gustafsson, J.A., et al. Investigations of a CA repeat in the oestrogen receptor beta gene in patients with Alzheimer's disease. Eur J Hum Genet, 2001, 9, 802-4.

[19] Lambert, J.C., Harris, J.M., Mann, D., Lemmon, H., Coates, J., Cumming, A., et al. Are the estrogen receptors involved in Alzheimer's disease? Neurosci Lett, 2001, 306, 193-7.

[20] Singh, M., Meyer, E.M., Millard, W.J., Simpkins, J.W. Ovarian steroid deprivation results in a reversible learning impairment and compromised cholinergic function in female Sprague-Dawley rats. Brain Res, 1994, 644, 305-12.

[21] Gibbs, R.B. Effects of gonadal hormone replacement on measures of basal forebrain cholinergic function. Neuroscience, 2000, 101, 931-8.

[22] Miller, M.M., Franklin, K.B. Theoretical basis for the benefit of postmenopausal estrogen substitution. Exp. Gerontol., 1999, 34, 587-604. 
[23] Gundlah, C., Lu, N.Z., Bethea, C.L. Ovarian steroid regulation of monoamine oxidase-A and -B mRNAs in the macaque dorsal raphe and hypothalamic nuclei. Psychopharmacology (Berl), 2002, 160, 271-82. Epub 2002 Jan 24

[24] Smith, L.J., Henderson, J.A., Abell, C.W., Bethea, C.L. Effects of Ovarian Steroids and Raloxifene on Proteins that Synthesize, Transport, and Degrade Serotonin in the Raphe Region of Macaques. Neuropsychopharmacology, 2004, 16, 16.

[25] Rupprecht, R., Di Michele, F., Hermann, B., Strohle, A., Lancel, M., Romeo, E., et al. Neuroactive steroids: molecular mechanisms of action and implications for neuropsychopharmacology. Brain. Res. Brain. Res. Rev., 2001, 37, 59-67.

[26] Behl, C., Holsboer, F. The female sex hormone oestrogen as a neuroprotectant. Trends. Pharmacol. Sci., 1999, 20, 441-4.

[27] Mcewen, B.S. Clinical review 108: The molecular and neuroanatomical basis for estrogen effects in the central nervous system. JClin Endocrinol \& Metabolism, 1999, 84, 1790-7.

[28] Coyle, J.T., Price, D.L., DeLong, M.R. Alzheimer's disease: a disorder of cortical cholinergic innervation. Science, 1983, 219, 1184-90.

[29] Chang, Q., Gold, P.E. Switching memory systems during learning: changes in patterns of brain acetylcholine release in the hippocampus and striatum in rats. JNeurosci, 2003, 23, 3001-5.

[30] Riecher-Rossler, A., Hafner, H. Schizophrenia and oestrogens--is there an association? Eur. Arch. Psychiatry. Clin. Neurosci., 1993, 242, 323-38.

[31] Majewska, M.D., Harrison, N.L., Schwartz, R.D., Barker, J.L., Paul, S.M. Steroid hormone metabolites are barbiturate-like modulators of the GABA receptor. Science, 1986, 232, 1004-7.

[32] Cabrera, R.J., Navarro, C.E. Progesterone in vitro increases NMDA-evoked [3H] dopamine release from striatal slices in proestrus rats. Neuropharmacology, 1996, 35, 175-8.

[33] Morissette, M., Di Paolo, T. Effect of chronic estradiol and progesterone treatments of ovariectomized rats on brain dopamine uptake sites. J. Neurochem., 1993, 60, 1876-83.

[34] Singer, C.A., Rogers, K.L., Strickland, T.M., Dorsa, D.M. Estrogen protects primary cortical neurons from glutamate toxicity. Neurosci Lett, 1996, 212, 13-6.

[35] Xu, H., Gouras, G.K., Greenfield, J.P., Vincent, B., Naslund, J., Mazzarelli, L., et al. Estrogen reduces neuronal generation of Alzheimer beta-amyloid peptides. Nat Med, 1998, 4, 447-51.

[36] Behl, C., Skutella, T., Lezoualc'h, F., Post, A., Widmann, M., Newton, C.J., et al. Neuroprotection against oxidative stress by estrogens: structure-activity relationship. Mol Pharmacol, 1997, 51, 535-41.

[37] Reiman, E.M., Armstrong, S.M., Matt, K.S., Mattox, J.H. The application of positron emission tomography to the study of the normal menstrual cycle. Hum Reprod, 1996, 11, 2799-805.

[38] Berman, K.F., Schmidt, P.J., Rubinow, D.R., Danaceau, M.A., Van Horn, J.D., Esposito, G., et al. Modulation of cognition-specific cortical activity by gonadal steroids: a positron-emission tomography study in women. Proc Natl Acad Sci US A, 1997, 94, 8836-41.

[39] Greene, R.A. Estrogen and cerebral blood flow: a mechanism to explain the impact of estrogen on the incidence and treatment of Alzheimer's disease. Int J Fertil Womens Med, 2000, 45, 253-7.

[40] Smith, Y.R., Zubieta, J.K. Neuroimaging of aging and estrogen effects on central nervous system physiology. Fertil Steril, 2001, 76, 651-9.

[41] Henderson, V.W. Estrogen, cognition, and a woman's risk of Alzheimer's disease. Am. J. Med., 1997, 103, $11 \mathrm{~S}-8 \mathrm{~S}$

[42] Smith, Y.R., Minoshima, S., Kuhl, D.E., Zubieta, J.K. Effects of long-term hormone therapy on cholinergic synaptic concentrations in healthy postmenopausal women. J Clin Endocrinol Metab, 2001, 86, 679-84.

[43] Gorski, R.A. In: S. Bhasin, H. Gabelnick, J. Spieler, R. Swerdloff, E. Wang, eds., Pharmacology, biology and clinical applications of androgens. New York, Wiley-Liss. 1996, pp. 159-68.

[44] Resnick, S.M., Berenbaum, S., Gottesman, I., Bouchard, T. Early hormonal influences on cognitive functioning in congenital adrenal hyperplasia. Dev Psychol, 1986, 22, 191-8.

[45] Ross, J.L., Roeltgen, D., Feuillan, P., Kushner, H., Cutler, G.B., Jr. Use of estrogen in young girls with Turner syndrome: effects on memory. Neurology, 2000, 54, 164-70.

[46] Ross, J.L., Roeltgen, D., Stefanatos, G.A., Feuillan, P., Kushner, H., Bondy, C., et al. Androgen-responsive aspects of cognition in girls with Turner syndrome. J Clin Endocrinol Metab, 2003, 88, 292-6.

[47] Sommer, B. In: J.T.E. Richardson, ed., Cognition and the menstrual cycle, Springer-Verlag. 1992; Vol. chapter 2, pp. 39-66.

[48] Jarvik, L.F. Human intelligence: sex differences. Acta. Genet. Med. Gemellol. (roma). 1975, 24, 189-211.

[49] Benbow, C.P., Stanley, J.C. Sex differences in mathematical reasoning ability: more facts. Science, 1983, 222, 1029-31. 
[50] Kimura, D. Sex, sexual orientation and sex hormones influence human cognitive function. Curr Opin Neurobiol, 1996, 6, 259-63.

[51] Halpern, D.F. Sex differences in intelligence. Implications for education. Am. Psychol., 1997, 52, 1091102.

[52] Sherwin, B.B. Oestrogen and cognitive function throughout the female lifespan. Novartis. Found. Symp., 2000, 230, 188-96.

[53] Sherwin, B.B. Estrogen and cognitive functioning in women. Endocr Rev, 2003, 24, 133-51.

[54] Compton, J., Van Amelsvoort, T., Murphy, D. HRT and its effect on normal ageing of the brain and dementia. Br. J. Clin. Pharmacol., 2001, 52, 647-53.

[55] Ganguli, M., Ratcliff, G., Huff, F.J., Belle, S., Kancel, M.J., Fischer, L., et al. Effects of age, gender, and education on cognitive tests in a rural elderly community sample: norms from the Monongahela Valley Independent Elders Survey. Neuroepidemiology, 1991, 10, 42-52.

[56] Barrett-Connor, E., Kritz-Silverstein, D. Gender differences in cognitive function with age: the Rancho Bernardo study. J. Am. Geriatr. Soc., 1999, 47, 159-64.

[57] Cohen, D., Wilkie, F. In: M.A. Wittig, A.C. Petersen, eds., Sex-related differences in cognitive functioning. New York, Academic Press. 1979, pp. 145-57.

[58] Mitchell, E.S., Woods, N.F. Midlife Women's attributions about perceived memory changes: observations from the Seattle Midlife Women's Health Study. J Women Health Gend Based Med, 2001, 10, 351-62.

[59] Henderson, V.W., Guthrie, J.R., Dudley, E.C., Burger, H.G., Dennerstein, L. Estrogen exposures and memory at midlife: a population-based study of women. Neurology, 2003, 60, 1369-71.

[60] Resnick, S.M., Metter, E.J., Zonderman, A.B. Estrogen replacement therapy and longitudinal decline in visual memory. A possible protective effect? Neurology, 1997, 49, 1491-7.

[61] Zandi, P.P., Carlson, M.C., Plassman, B.L., Welsh-Bohmer, K.A., Mayer, L.S., Steffens, D.C., et al. Hormone replacement therapy and incidence of Alzheimer disease in older women: the Cache County Study. Jama, 2002, 288, 2123-9.

[62] Meyer, P.M., Powell, L.H., Wilson, R.S., Everson-Rose, S.A., Kravitz, H.M., Luborsky, J.L., et al. A population-based longitudinal study of cognitive functioning in the menopausal transition. Neurology, 2003, 61, 801-6.

[63] Gannon, L. Women and aging: transcending the myths: New York 1999.

[64] Sherwin, B.B. Estrogen and/or androgen replacement therapy and cognitive functioning in surgically menopausal women. Psychoneuroendocrinology, 1988, 13, 345-57.

[65] Nappi, R.E., Sinforiani, E., Mauri, M., Bono, G., Polatti, F., Nappi, G. Memory functioning at menopause: impact of age in ovariectomized women. Gynecol Obstet Invest, 1999, 47, 29-36.

[66] Muscari Lin, E., Aikin, J.L., Good, B.C. Premature menopause after cancer treatment. Cancer Pract, 1999, 7, 114-21.

[67] Evans, D.A. Estimated prevalence of Alzheimer's disease in the United States. Milbank. Q., 1990, 68, $267-$ 89

[68] Ritchie, K., Kildea, D. Is senile dementia "age-related" or "ageing-related"?--evidence from meta-analysis of dementia prevalence in the oldest old. Lancet, 1995, 346, 931-4.

[69] Ott, A., Breteler, M.M., Van Harskamp, F., Claus, J.J., Van Der Cammen, T.J., Grobbee, D.E., et al. Prevalence of Alzheimer's disease and vascular dementia: association with education. The Rotterdam study. Bmj, 1995, 310, 970-93.

[70] Andersen, K., Launer, L.J., Dewey, M.E., Letenneur, L., Ott, A., Copeland, J.R., et al. Gender differences in the incidence of $\mathrm{AD}$ and vascular dementia: The EURODEM Studies. EURODEM Incidence Research Group. Neurology, 1999, 53, 1992-7.

[71] Wade, J.P., Mirsen, T.R., Hachinski, V.C., Fisman, M., Lau, C., Merskey, H. The clinical diagnosis of Alzheimer's disease. Arch. Neurol., 1987, 44, 24-9.

[72] Gao, S., Hendrie, H.C., Hall, K.S., Hui, S. The relationships between age, sex, and the incidence of dementia and Alzheimer disease: a meta-analysis. Arch Gen Psychiatry, 1998, 55, 809-15.

[73] Edland, S.D., Rocca, W.A., Petersen, R.C., Cha, R.H., Kokmen, E. Dementia and Alzheimer disease incidence rates do not vary by sex in Rochester, Minn. Arch Neurol, 2002, 59, 1589-93.

[74] Morris, J.C., Heyman, A., Mohs, R.C., Hughes, J.P., van Belle, G., Fillenbaum, G., et al. The Consortium to Establish a Registry for Alzheimer's Disease (CERAD). Part I. Clinical and neuropsychological assessment of Alzheimer's disease. Neurology, 1989, 39, 1159-65.

[75] Buckwalter, J.G., Sobel, E., Dunn, M.E., Diz, M.M., Henderson, V.W. Gender differences on a brief measure of cognitive functioning in Alzheimer's disease. Arch. Neurol., 1993, 50, 757-60.

[76] Henderson, V.W., Buckwalter, J.G. Cognitive deficits of men and women with Alzheimer's disease. Neurology 1994, 44, 90-6. 
[77] Ripich, D.N., Petrill, S.A., Whitehouse, P.J., Ziol, E.W. Gender differences in language of AD patients: a longitudinal study. Neurology, 1995, 45, 299-302.

[78] Bayles, K.A., Azuma, T., Cruz, R.F., Tomoeda, C.K., Wood, J.A., Montgomery, E.B., Jr. Gender differences in language of Alzheimer disease patients revisited. Alzheimer Dis Assoc Disord, 1999, 13, $138-46$.

[79] Arpels, J.C. The female brain hypoestrogenic continuum from the premenstrual syndrome to menopause. A hypothesis and review of supporting data. J. Reprod. Med., 1996, 41, 633-69.

[80] Pearlstein, T., Rosen, K., Stone, A.B. Mood disorders and menopause. Endocrinol. Metab. Clin. North. Am., 1997, 26, 279-94.

[81] Grigoriadis, S., Kennedy, S.H. Role of estrogen in the treatment of depression. Am J Ther, 2002, 9, 503-9.

[82] Rozenberg, S., Fellemans, C., Kroll, M., Vandromme, J. The menopause in Europe. Int. J. Fertil. Womens. Med., 2000, 45, 182-9.

[83] Kloosterboer, H.J., Ederveen, A.G. Pros and cons of existing treatment modalities in osteoporosis: a comparison between tibolone, SERMs and estrogen (+/-progestogen) treatments. J Steroid Biochem Mol Biol, 2002, 83, 157-65.

[84] Zec, R.F., Trivedi, M.A. Effects of hormone replacement therapy on cognitive aging and dementia risk in postmenopausal women: a review of ongoing large-scale, long-term clinical trials. Climacteric, 2002, 5, $122-34$

[85] File, S.E., Heard, J.E., Rymer, J. Trough oestradiol levels associated with cognitive impairment in postmenopausal women after 10 years of oestradiol implants. Psychopharmacology (Berl), 2002, 161, 107-12. Epub 2002 Feb 21.

[86] Phillips, S.M., Sherwin, B.B. Effects of estrogen on memory function in surgically menopausal women. Psychoneuroendocrinology, 1992, 17, 485-95.

[87] Duka, T., Tasker, R., Mcgowan, J.F. The effects of 3-week estrogen hormone replacement on cognition in elderly healthy females. Psychopharmacology. (berl). 2000, 149, 129-39.

[88] Leblanc, E.S., Janowsky, J., Chan, B.K., Nelson, H.D. Hormone replacement therapy and cognition: systematic review and meta-analysis. Jama, 2001, 285, 1489-99.

[89] Hogervorst, E., Yaffe, K., Richards, M., Huppert, F. Hormone replacement therapy for cognitive function in postmenopausal women. Cochrane. Database. Syst. Rev., 2002, CD0031.

[90] Maki, P., Hogervorst, E. The menopause and HRT. HRT and cognitive decline. Best Pract Res Clin Endocrinol Metab, 2003, 17, 105-22.

[91] Rice, K., Morse, C. Measuring cognition in menopause research: a review of test use. Climacteric, 2003, 6 , $2-22$.

[92] Barrett-Connor, E., Kritz-Silverstein, D. Estrogen replacement therapy and cognitive function in older women. Jama, 1993, 269, 2637-41.

[93] Polo-Kantola, P., Portin, R., Polo, O., Helenius, H., Irjala, K., Erkkola, R. The effect of short-term estrogen replacement therapy on cognition: a randomized, double-blind, cross-over trial in postmenopausal women. Obstet Gynecol, 1998, 91, 459-66.

[94] Carlson, L.E., Sherwin, B.B. Steroid hormones, memory and mood in a healthy elderly population. Psychoneuroendocrinology, 1998, 23, 583-603.

[95] Kimura, D. Estrogen replacement therapy may protect against intellectual decline in postmenopausal women. Horm. Behav., 1995, 29, 312-21.

[96] Drake, E.B., Henderson, V.W., Stanczyk, F.Z., Mccleary, C.A., Brown, W.S., Smith, C.A., et al. Associations between circulating sex steroid hormones and cognition in normal elderly women. Neurology, 2000, 54, 599-603.

[97] Linzmayer, L., Semlitsch, H.V., Saletu, B., Bock, G., Saletu-zyhlarz, G., Zoghlami, A., et al. Double-blind, placebo-controlled psychometric studies on the effects of a combined estrogen-progestin regimen versus estrogen alone on performance, mood and personality of menopausal syndrome patients. Arzneimittelforschung, 2001, 51, 238-45.

[98] Resnick, S.M., Maki, P.M. Effects of hormone replacement therapy on cognitive and brain aging. Ann. $N$. Y. Acad. Sci., 2001, 949, 203-14.

[99] Toran-allerand, C.D. Estrogen as a treatment for Alzheimer disease. Jama 2000, 284, 307-8.

[100] Rapp, S.R., Espeland, M.A., Shumaker, S.A., Henderson, V.W., Brunner, R.L., Manson, J.E., et al. Effect of estrogen plus progestin on global cognitive function in postmenopausal women: the Women's Health Initiative Memory Study: a randomized controlled trial. Jama, 2003, 289, 2663-72.

[101] Writing Group for the Women's Health Initiative Investigators. Risks and benefits of estrogen plus progestin in healthy postmenopausal women. Jama, 2002, 288, 321-33. 
[102] Anderson, G.L., Limacher, M., Assaf, A.R., Bassford, T., Beresford, S.A., Black, H., et al. Effects of conjugated equine estrogen in postmenopausal women with hysterectomy: the Women's Health Initiative randomized controlled trial. Jama, 2004, 291, 1701-12.

[103] Espeland, M.A., Rapp, S.R., Shumaker, S.A., Brunner, R., Manson, J.E., Sherwin, B.B., et al. Conjugated equine estrogens and global cognitive function in postmenopausal women: Women's Health Initiative Memory Study. Jama, 2004, 291, 2959-68.

[104] Amaducci, L.A., Fratiglioni, L., Rocca, W.A., Fieschi, C., Livrea, P., Pedone, D., et al. Risk factors for clinically diagnosed Alzheimer's disease: a case-control study of an Italian population. Neurology, 1986, 36, 922-31

[105] Heyman, A., Wilkinson, W.E., Stafford, J.A., Helms, M.J., Sigmon, A.H., Weinberg, T. Alzheimer's disease: a study of epidemiological aspects. Ann. Neurol., 1984, 15, 335-41.

[106] Graves, A.B., White, E., Koepsell, T.D., Reifler, B.V., Van Belle, G., Larson, E.B., et al. A case-control study of Alzheimer's disease. Ann. Neurol., 1990, 28, 766-74.

[107] Brenner, D.E., Kukull, W.A., Stergachis, A., Van Belle, G., Bowen, J.D., Mccormick, W.C., et al. Postmenopausal estrogen replacement therapy and the risk of Alzheimer's disease: a population-based case-control study. Am. J. Epidemiol., 1994, 140, 262-7.

[108] Seshadri, S., Zornberg, G.L., Derby, L.E., Myers, M.W., Jick, H., Drachman, D.A. Postmenopausal estrogen replacement therapy and the risk of Alzheimer disease. Arch Neurol, 2001, 58, 435-40.

[109] Paganini-Hill, A., Henderson, V.W. Estrogen deficiency and risk of Alzheimer's disease in women. Am. J. Epidemiol., 1994, 140, 256-61.

[110] Broe, G.A., Henderson, A.S., Creasey, H., McCusker, E., Korten, A.E., Jorm, A.F., et al. A case-control study of Alzheimer's disease in Australia. Neurology, 1990, 40, 1698-707.

[111] Henderson, V.W., Paganini-hill, A., Emanuel, C.K., Dunn, M.E., Buckwalter, J.G. Estrogen replacement therapy in older women. Comparisons between Alzheimer's disease cases and nondemented control subjects. Arch. Neurol., 1994, 51, 896-900.

[112] Waring, S.C., Rocca, W.A., Petersen, R.C., O'brien, P.C., Tangalos, E.G., Kokmen, E. Postmenopausal estrogen replacement therapy and risk of AD: a population-based study. Neurology, 1999, 52, 965-70.

[113] Mortel, K.F., Meyer, J.S. Lack of postmenopausal estrogen replacement therapy and the risk of dementia. J. Neuropsychiatry. Clin. Neurosci., 1995, 7, 334-7.

[114] Slooter, A.J., Bronzova, J., Witteman, J.C., Van Broeckhoven, C., Hofman, A., van Duijn, C.M. Estrogen use and early onset Alzheimer's disease: a population-based study. J Neurol Neurosurg Psychiatry, 1999, 67, 779-81

[115] Lerner, A., Koss, E., Debanne, S., Rowland, D., Smyth, K., Friedland, R. Smoking and oestrogenreplacement therapy as protective factors for Alzheimer's disease. Lancet, 1997, 349, 403-4.

[116] Baldereschi, M., Di Carlo, A., Lepore, V., Bracco, L., Maggi, S., Grigoletto, F., et al. Estrogenreplacement therapy and Alzheimer's disease in the Italian Longitudinal Study on Aging. Neurology, 1998, 50, 996-1002.

[117] Tang, M.X., Jacobs, D., Stern, Y., Marder, K., Schofield, P., Gurland, B., et al. Effect of oestrogen during menopause on risk and age at onset of Alzheimer's disease. Lancet, 1996, 348, 429-32.

[118] Kawas, C., Resnick, S., Morrison, A., Brookmeyer, R., Corrada, M., Zonderman, A., et al. A prospective study of estrogen replacement therapy and the risk of developing Alzheimer's disease: the Baltimore Longitudinal Study of Aging. Neurology, 1997, 48, 1517-21.

[119] Yaffe, K., Sawaya, G., Lieberburg, I., Grady, D. Estrogen therapy in postmenopausal women: effects on cognitive function and dementia. Jama, 1998, 279, 688-95.

[120] Hogervorst, E., Williams, J., Budge, M., Riedel, W., Jolles, J. The nature of the effect of female gonadal hormone replacement therapy on cognitive function in post-menopausal women: a meta-analysis. Neuroscience, 2000, 101, 485-512.

[121] Shumaker, S.A., Legault, C., Thal, L., Wallace, R.B., Ockene, J.K., Hendrix, S.L., et al. Estrogen plus progestin and the incidence of dementia and mild cognitive impairment in postmenopausal women: the Women's Health Initiative Memory Study: a randomized controlled trial. Jama, 2003, 289, 2651-62.

[122] Shumaker, S.A., Legault, C., Kuller, L., Rapp, S.R., Thal, L., Lane, D.S., et al. Conjugated equine estrogens and incidence of probable dementia and mild cognitive impairment in postmenopausal women: Women's Health Initiative Memory Study. Jama, 2004, 291, 2947-58.

[123] Yaffe, K. Hormone therapy and the brain: deja vu all over again? Jama, 2003, 289, 2717-9.

[124] Wassertheil-Smoller, S., Hendrix, S.L., Limacher, M., Heiss, G., Kooperberg, C., Baird, A., et al. Effect of estrogen plus progestin on stroke in postmenopausal women: the Women's Health Initiative: a randomized trial. Jama, 2003, 289, 2673-84 
[125] Grodstein, F., Clarkson, T.B., Manson, J.E. Understanding the divergent data on postmenopausal hormone therapy. N Engl JMed, 2003, 348, 645-50.

[126] Vermeer, S.E., Prins, N.D., den Heijer, T., Hofman, A., Koudstaal, P.J., Breteler, M.M. Silent brain infarcts and the risk of dementia and cognitive decline. $N$ Engl JMed, 2003, 348, 1215-22.

[127] Henderson, V.W., Paganini-hill, A., Miller, B.L., Elble, R.J., Reyes, P.F., Shoupe, D., et al. Estrogen for Alzheimer's disease in women: randomized, double-blind, placebo-controlled trial. Neurology, 2000, 54, 295-301.

[128] Mulnard, R.A., Cotman, C.W., Kawas, C., Van Dyck, C.H., Sano, M., Doody, R., et al. Estrogen replacement therapy for treatment of mild to moderate Alzheimer disease: a randomized controlled trial. Alzheimer's Disease Cooperative Study. Jama, 2000, 283, 1007-15.

[129] Wang, P.N., Liao, S.Q., Liu, R.S., Liu, C.Y., Chao, H.T., Lu, S.R., et al. Effects of estrogen on cognition, mood, and cerebral blood flow in AD: a controlled study. Neurology, 2000, 54, 2061-6.

[130] Asthana, S., Baker, L.D., Craft, S., Stanczyk, F.Z., Veith, R.C., Raskind, M.A., et al. High-dose estradiol improves cognition for women with AD: results of a randomized study. Neurology, 2001, 57, 605-12.

[131] Hogervorst, E., Yaffe, K., Richards, M., Huppert, F. Hormone replacement therapy to maintain cognitive function in women with dementia (Cochrane Review). Cochrane. Database. Syst. Rev., 2002, CD0037.

[132] Schneider, L.S., Farlow, M.R., Henderson, V.W., Pogoda, J.M. Effects of estrogen replacement therapy on response to tacrine in patients with Alzheimer's disease. Neurology 1996, 46, 1580-4.

[133] Schneider, L.S., Farlow, M. Combined tacrine and estrogen replacement therapy in patients with Alzheimer's disease. Ann. N. Y. Acad. Sci., 1997, 826, 317-22.

[134] Rigaud, A.S., Andre, G., Vellas, B., Touchon, J., Pere, J.J. No additional benefit of HRT on response to rivastigmine in menopausal women with AD. Neurology, 2003, 60, 148-9.

[135] Farlow, M.R., Lahiri, D.K., Poirier, J., Davignon, J., Schneider, L., Hui, S.L. Treatment outcome of tacrine therapy depends on apolipoprotein genotype and gender of the subjects with Alzheimer's disease. Neurology, 1998, 50, 669-77.

[136] Brinton, R.D. Impact of estrogen therapy on Alzheimer's disease: a fork in the road? CNS Drugs, 2004, 18, 405-22.

[137] Yaffe, K., Haan, M., Byers, A., Tangen, C., Kuller, L. Estrogen use, APOE, and cognitive decline: evidence of gene-environment interaction. Neurology, 2000, 54, 1949-54.

[138] Greendale, G.A., Reboussin, B.A., Hogan, P., Barnabei, V.M., Shumaker, S., Johnson, S., et al. Symptom relief and side effects of postmenopausal hormones: results from the Postmenopausal Estrogen/Progestin Interventions Trial. Obstet. Gynecol., 1998, 92, 982-8.

[139] Zec, R.F., Trivedi, M.A. The effects of estrogen replacement therapy on neuropsychological functioning in postmenopausal women with and without dementia: a critical and theoretical review. Neuropsychol Rev, 2002, 12, 65-109.

[140] O'Connell, M.B. Pharmacokinetic and pharmacologic variation between different estrogen products. $J$ Clin Pharmacol, 1995, 35, 18S-24S.

[141] Reboussin, B.A., Greendale, G.A., Espeland, M.A. Effect of hormone replacement therapy on self-reported cognitive symptoms: results from the Postmenopausal Estrogen/Progestin Interventions (PEPI) trial. Climacteric, 1998, 1, 172-9.

[142] Brown, T.J., Scherz, B., Hochberg, R.B., MacLusky, N.J. Regulation of estrogen receptor concentrations in the rat brain: effects of sustained androgen and estrogen exposure. Neuroendocrinology, 1996, 63, 53-60

[143] Scott, R.T., Jr., Ross, B., Anderson, C., Archer, D.F. Pharmacokinetics of percutaneous estradiol: a crossover study using a gel and a transdermal system in comparison with oral micronized estradiol. Obstet Gynecol, 1991, 77, 758-64.

[144] Wakatsuki, A., Okatani, Y., Ikenoue, N., Fukaya, T. Different effects of oral conjugated equine estrogen and transdermal estrogen replacement therapy on size and oxidative susceptibility of low-density lipoprotein particles in postmenopausal women. Circulation, 2002, 106, 1771-6.

[145] Oger, E., Alhenc-Gelas, M., Lacut, K., Blouch, M.T., Roudaut, N., Kerlan, V., et al. Differential Effects of Oral and Transdermal Estrogen/Progesterone Regimens on Sensitivity to Activated Protein C Among Postmenopausal Women. A Randomized Trial. Arterioscler Thromb Vasc Biol, 2003, 17, 17.

[146] Scarabin, P.Y., Alhenc-Gelas, M., Plu-Bureau, G., Taisne, P., Agher, R., Aiach, M. Effects of oral and transdermal estrogen/progesterone regimens on blood coagulation and fibrinolysis in postmenopausal women. A randomized controlled trial. Arterioscler Thromb Vasc Biol, 1997, 17, 3071-8.

[147] Vehkavaara, S., Silveira, A., Hakala-Ala-Pietila, T., Virkamaki, A., Hovatta, O., Hamsten, A., et al. Effects of oral and transdermal estrogen replacement therapy on markers of coagulation, fibrinolysis, inflammation and serum lipids and lipoproteins in postmenopausal women. Thromb Haemost, 2001, 85, 619-25. 
[148] Decensi, A., Omodei, U., Robertson, C., Bonanni, B., Guerrieri-Gonzaga, A., Ramazzotto, F., et al. Effect of transdermal estradiol and oral conjugated estrogen on C-reactive protein in retinoid-placebo trial in healthy women. Circulation, 2002, 106, 1224-8.

[149] Scarabin, P.Y., Oger, E., Plu-Bureau, G. Differential association of oral and transdermal oestrogenreplacement therapy with venous thromboembolism risk. Lancet, 2003, 362, 428-32.

[150] Miyagawa, K., Rosch, J., Stanczyk, F., Hermsmeyer, K. Medroxyprogesterone interferes with ovarian steroid protection against coronary vasospasm. Nat Med, 1997, 3, 324-7.

[151] Otsuki, M., Saito, H., Xu, X., Sumitani, S., Kouhara, H., Kishimoto, T., et al. Progesterone, but not medroxyprogesterone, inhibits vascular cell adhesion molecule-1 expression in human vascular endothelial cells. Arterioscler Thromb Vasc Biol, 2001, 21, 243-8

[152] Hofseth, L.J., Raafat, A.M., Osuch, J.R., Pathak, D.R., Slomski, C.A., Haslam, S.Z. Hormone replacement therapy with estrogen or estrogen plus medroxyprogesterone acetate is associated with increased epithelial proliferation in the normal postmenopausal breast. J Clin Endocrinol Metab, 1999, 84, 4559-65.

[153] Foidart, J.M., Colin, C., Denoo, X., Desreux, J., Beliard, A., Fournier, S., et al. Estradiol and progesterone regulate the proliferation of human breast epithelial cells. Fertil Steril, 1998, 69, 963-9.

[154] Beral, V. Breast cancer and hormone-replacement therapy in the Million Women Study. Lancet, 2003, 362, 419-27.

[155] de Lignieres, B., de Vathaire, F., Fournier, S., Urbinelli, R., Allaert, F., Le, M.G., et al. Combined hormone replacement therapy and risk of breast cancer in a French cohort study of 3175 women. Climacteric, 2002, $5,332-40$.

[156] Register, T.C., Adams, M.R., Golden, D.L., Clarkson, T.B. Conjugated equine estrogens alone, but not in combination with medroxyprogesterone acetate, inhibit aortic connective tissue remodeling after plasma lipid lowering in female monkeys. Arterioscler Thromb Vasc Biol, 1998, 18, 1164-71.

[157] Grodstein, F., Manson, J.E., Colditz, G.A., Willett, W.C., Speizer, F.E., Stampfer, M.J. A prospective, observational study of postmenopausal hormone therapy and primary prevention of cardiovascular disease. Ann Intern Med, 2000, 133, 933-41.

[158] Nilsen, J., Brinton, R.D. Impact of progestins on estrogen-induced neuroprotection: synergy by progesterone and 19-norprogesterone and antagonism by medroxyprogesterone acetate. Endocrinology, 2002, 143, 205-12.

[159] Nilsen, J., Brinton, R.D. Divergent impact of progesterone and medroxyprogesterone acetate (Provera) on nuclear mitogen-activated protein kinase signaling. Proc Natl Acad Sci US A, 2003, 100, 10506-11. Epub 2003 Aug 18

[160] Rice, M.M., Graves, A.B., McCurry, S.M., Gibbons, L.E., Bowen, J.D., McCormick, W.C., et al. Postmenopausal estrogen and estrogen-progestin use and 2-year rate of cognitive change in a cohort of older Japanese American women: The Kame Project. Arch Intern Med, 2000, 160, 1641-9.

[161] Minkin, M.J. Considerations in the choice of oral vs. transdermal hormone therapy: a review. J Reprod Med, 2004, 49, 311-20.

[162] Bryant, H.U., Dere, W.H. Selective estrogen receptor modulators: an alternative to hormone replacement therapy. Proc. Soc. Exp. Biol. Med., 1998, 217, 45-52.

[163] Phillips, K.A., Bernhard, J. Adjuvant breast cancer treatment and cognitive function: current knowledge and research directions. $J$ Natl Cancer Inst, 2003, 95, 190-7.

[164] Paganini-Hill, A., Clark, L.J. Preliminary assessment of cognitive function in breast cancer patients treated with tamoxifen. Breast. Cancer. Res. Treat., 2000, 64, 165-76.

[165] Van Dam, F.S., Schagen, S.B., Muller, M.J., Boogerd, W., Vd Wall, L.E., Droogleever Fortuyn, M.E., et al. Impairment of cognitive function in women receiving adjuvant treatment for high-risk breast cancer: high-dose versus standard-dose chemotherapy. J. Natl. Cancer. Inst., 1998, 90, 210-8.

[166] Nickelsen, T., Lufkin, E.G., Riggs, B.L., Cox, D.A., Crook, T.H. Raloxifene hydrochloride, a selective estrogen receptor modulator: safety assessment of effects on cognitive function and mood in postmenopausal women. Psychoneuroendocrinology, 1999, 24, 115-28.

[167] Yaffe, K., Krueger, K., Sarkar, S., Grady, D., Barrett-connor, E., Cox, D.A., et al. Cognitive function in postmenopausal women treated with raloxifene. N. Engl. J. Med. , 2001, 344, 1207-13.

[168] Littleton-Kearney, M.T., Ostrowski, N.L., Cox, D.A., Rossberg, M.I., Hurn, P.D. Selective estrogen receptor modulators: tissue actions and potential for CNS protection. CNS Drug Rev, 2002, 8, 309-30.

[169] Sherwin, B.B., Tulandi, T. "Add-back" estrogen reverses cognitive deficits induced by a gonadotropinreleasing hormone agonist in women with leiomyomata uteri [see comments. J. Clin. Endocrinol. Metab., 1996, 81, 2545-9.

[170] Simpson, E., Rubin, G., Clyne, C., Robertson, K., O'donnell, L., Jones, M., et al. The role of local estrogen biosynthesis in males and females. Trends. Endocrinol. Metab., 2000, 11, 184-8. 
[171] Van Pottelbergh, I., Goemaere, S., Kaufman, J.M. Bioavailable estradiol and an aromatase gene polymorphism are determinants of bone mineral density changes in men over 70 years of age. $J$ Clin Endocrinol Metab, 2003, 88, 3075-81.

[172] Hogervorst, E., De Jager, C., Budge, M., Smith, A.D. Serum levels of estradiol and testosterone and performance in different cognitive domains in healthy elderly men and women. Psychoneuroendocrinology, 2004, 29, 405-21.

[173] Senanarong, V., Vannasaeng, S., Poungvarin, N., Ploybutr, S., Udompunthurak, S., Jamjumras, P., et al. Endogenous estradiol in elderly individuals: cognitive and noncognitive associations. Arch. Neurol., 2002, 59, 385-9.

[174] Manly, J.J., Merchant, C.A., Jacobs, D.M., Small, S.A., Bell, K., Ferin, M., et al. Endogenous estrogen levels and Alzheimer's disease among postmenopausal women. Neurology, 2000, 54, 833-7.

[175] Thal, L.J., Thomas, R.G., Mulnard, R., Sano, M., Grundman, M., Schneider, L. Estrogen levels do not correlate with improvement in cognition. Arch Neurol, 2003, 60, 209-12.

[176] Geerlings, M.I., Launer, L.J., de Jong, F.H., Ruitenberg, A., Stijnen, T., van Swieten, J.C., et al. Endogenous estradiol and risk of dementia in women and men: the Rotterdam Study. Ann Neurol, 2003, 53, 607-15.

[177] Rasmuson, S., Nasman, B., Carlstrom, K., Olsson, T. Increased levels of adrenocortical and gonadal hormones in mild to moderate Alzheimer's disease. Dement Geriatr Cogn Disord, 2002, 13, 74-9.

[178] Hogervorst, E., Williams, J., Budge, M., Barnetson, L., Combrinck, M., Smith, A.D. Serum total testosterone is lower in men with Alzheimer's disease. Neuroendocrinol. Lett., 2001, 22, 163-8.

[179] Hogervorst, E., Williams, J., Combrinck, M., David Smith, A. Measuring serum oestradiol in women with Alzheimer's disease: the importance of the sensitivity of the assay method. Eur $J$ Endocrinol, 2003, 148, 67-72.

[180] Bowen, R.L., Isley, J.P., Atkinson, R.L. An association of elevated serum gonadotropin concentrations and Alzheimer disease? J Neuroendocrinol, 2000, 12, 351-4.

[181] Bowen, R.L., Smith, M.A., Harris, P.L., Kubat, Z., Martins, R.N., Castellani, R.J., et al. Elevated luteinizing hormone expression colocalizes with neurons vulnerable to Alzheimer's disease pathology. $J$ Neurosci Res, 2002, 70, 514-8.

[182] Barrett-Connor, E., Mueller, J.E., Von Muhlen, D.G., Laughlin, G.A., Schneider, D.L., Sartoris, D.J. Low levels of estradiol are associated with vertebral fractures in older men, but not women: the Rancho Bernardo Study. J. Clin. Endocrinol. Metab., 2000, 85, 219-23.

[183] Key, T.J., Verkasalo, P.K., Banks, E. Epidemiology of breast cancer. Lancet Oncol, 2001, 2, 133-40.

[184] Kuchel, G.A., Tannenbaum, C., Greenspan, S.L., Resnick, N.M. Can variability in the hormonal status of elderly women assist in the decision to administer estrogens? J. Womens. Health. Gend. Based. Med., 2001, 10, 109-16.

[185] Berlinger, W.G., Potter, J.F. Low Body Mass Index in demented outpatients. J. Am. Geriatr. Soc., 1991, 39, 973-8.

[186] Wardlaw, G.M. Putting body weight and osteoporosis into perspective. Am. J. Clin. Nutr., 1996, 63, 433S$6 \mathrm{~S}$.

[187] Huang, Z., Hankinson, S.E., Colditz, G.A., Stampfer, M.J., Hunter, D.J., Manson, J.E., et al. Dual effects of weight and weight gain on breast cancer risk. Jama, 1997, 278, 1407-11.

[188] Brett, M., Baxendale, S. Motherhood and memory: a review. Psychoneuroendocrinology, 2001, 26, 33962.

[189] Zmuda, J.M., Cauley, J.A., Ljung, B.M., Bauer, D.C., Cummings, S.R., Kuller, L.H. Bone mass and breast cancer risk in older women: differences by stage at diagnosis. $J$ Natl Cancer Inst, 2001, 93, 930-6.

[190] Buist, D.S., LaCroix, A.Z., Barlow, W.E., White, E., Weiss, N.S. Bone mineral density and breast cancer risk in postmenopausal women. J Clin Epidemiol, 2001, 54, 417-22.

[191] Cauley, J.A., Lucas, F.L., Kuller, L.H., Vogt, M.T., Browner, W.S., Cummings, S.R. Bone mineral density and risk of breast cancer in older women: the study of osteoporotic fractures. Study of Osteoporotic Fractures Research Group. Jama, 1996, 276, 1404-8

[192] van der Klift, M., Laet, C.E., Coebergh, J.W., Hofman, A., Pols, H.A. Bone mineral density and the risk of breast cancer: the Rotterdam Study. Bone, 2003, 32, 211-6.

[193] Zhang, Y., Felson, D.T., Ellison, R.C., Kreger, B.E., Schatzkin, A., Dorgan, J.F., et al. Bone mass and the risk of colon cancer among postmenopausal women: the Framingham study. Am. J. Epidemiol., 2001, 153, 31-7.

[194] Yaffe, K., Browner, W., Cauley, J., Launer, L., Harris, T. Association between bone mineral density and cognitive decline in older women. J. Am. Geriatr. Soc., 1999, 47, 1176-82. 
[195] Zhang, Y., Seshadri, S., Ellison, R.C., Heeren, T., Felson, D.T. Bone mineral density and verbal memory impairment: Third National Health and Nutrition Examination Survey. Am. J. Epidemiol., 2001, 154, 795802 .

[196] Lui, L.Y., Stone, K., Cauley, J.A., Hillier, T., Yaffe, K. Bone loss predicts subsequent cognitive decline in older women: the study of osteoporotic fractures. J Am Geriatr Soc, 2003, 51, 38-43.

[197] Johnston, C.C.J., Slemenda, C.W. Pathogenesis of osteoporosis. Bone, 1995, 17, 19S-22S

[198] Daling, J.R., Brinton, L.A., Voigt, L.F., Weiss, N.S., Coates, R.J., Malone, K.E., et al. Risk of breast cancer among white women following induced abortion. Am. J. Epidemiol., 1996, 144, 373-80.

[199] Petrakis, N.L., Wrensch, M.R., Ernster, V.L., Miike, R., Murai, J., Simberg, N., et al. Influence of pregnancy and lactation on serum and breast fluid estrogen levels: implications for breast cancer risk. Int. J. Cancer., 1987, 40, 587-91.

[200] Titus-Ernstoff, L., Perez, K., Cramer, D.W., Harlow, B.L., Baron, J.A., Greenberg, E.R. Menstrual and reproductive factors in relation to ovarian cancer risk. Br J Cancer, 2001, 84, 714-21.

[201] Colditz, G.A., Frazier, A.L. Models of breast cancer show that risk is set by events of early life: prevention efforts must shift focus. Cancer. Epidemiol. Biomarkers. Prev., 1995, 4, 567-71.

[202] Pike, M.C., Krailo, M.D., Henderson, B.E., Casagrande, J.T., Hoel, D.G. 'Hormonal' risk factors, 'breast tissue age' and the age-incidence of breast cancer. Nature, 1983, 303, 767-70.

[203] Pathak, D.R., Osuch, J.R., He, J. Breast carcinoma etiology: current knowledge and new insights into the effects of reproductive and hormonal risk factors in black and white populations. Cancer, 2000, 88, 12308 .

[204] Rautalahti, M., Albanes, D., Virtamo, J., Palmgren, J., Haukka, J., Heinonen, O.P. Lifetime menstrual activity--indicator of breast cancer risk. Eur. J. Epidemiol., 1993, 9, 17-25.

[205] Nguyen, T.V., Jones, G., Sambrook, P.N., White, C.P., Kelly, P.J., Eisman, J.A. Effects of estrogen exposure and reproductive factors on bone mineral density and osteoporotic fractures. J. Clin. Endocrinol. Metab., 1995, 80, 2709-14.

[206] Fox, K.M., Magaziner, J., Sherwin, R., Scott, J.C., Plato, C.C., Nevitt, M., et al. Reproductive correlates of bone mass in elderly women. Study of Osteoporotic Fractures Research Group. J. Bone. Miner. Res., 1993, 8, 901-8.

[207] Michaelsson, K., Baron, J.A., Johnell, O., Persson, I., Ljunghall, S. Variation in the efficacy of hormone replacement therapy in the prevention of hip fracture. Swedish Hip Fracture Study Group. Osteoporos. Int., 1998, 8, 540-6.

[208] Michaelsson, K., Baron, J.A., Farahmand, B.Y., Persson, I., Ljunghall, S. Oral-contraceptive use and risk of hip fracture: a case-control study Lancet, 1999, 353, 1481-4.

[209] Smith, C.A., Mccleary, C.A., Murdock, G.A., Wilshire, T.W., Buckwalter, D.K., Bretsky, P., et al. Lifelong estrogen exposure and cognitive performance in elderly women. Brain. Cogn., 1999, 39, 203-18.

[210] McLay, R.N., Maki, P.M., Lyketsos, C.G. Nulliparity and late menopause are associated with decreased cognitive decline. $J$ Neuropsychiatry Clin Neurosci, 2003, 15, 161-7.

[211] Richards, M., Kuh, D., Hardy, R., Wadsworth, M. Lifetime cognitive function and timing of the natural menopause. Neurology, 1999, 53, 308-14

[212] Ptok, U., Barkow, K., Heun, R. Fertility and number of children in patients with Alzheimer's disease. Arch Women Ment Health, 2002, 5, 83-6.

[213] van Duijn, C.M. Menopause and the brain. JPsychosom Obstet Gynaecol, 1997, 18, 121-5.

[214] Geerlings, M.I., Ruitenberg, A., Witteman, J.C., Van Swieten, J.C., Hofman, A., Van Duijn, C.M., et al. Reproductive period and risk of dementia in postmenopausal women. Jama, 2001, 285, 1475-81.

[215] Marx, J. Searching for drugs that combat Alzheimer's. Science, 1996, 273, 50-3.

[216] Henderson, V.W. Hormone therapy and the brain: A clinical perspective on the role of estrogen, Parthenon Publishing: New York/ London 2000.

[217] Brookmeyer, R., Gray, S., Kawas, C. Projections of Alzheimer's disease in the United States and the public health impact of delaying disease onset.PG - 1337-42. Am J Public Health, 1998, 88, 1337-42.

[218] Hampson, E. Variations in sex-related cognitive abilities across the menstrual cycle. Brain. Cogn., 1990, 14, 26-43.

[219] Hampson, E. Estrogen-related variations in human spatial and articulatory-motor skills. Psychoneuroendocrinology, 1990, 15, 97-111.

[220] Phillips, S.M., Sherwin, B.B. Variations in memory function and sex steroid hormones across the menstrual cycle. Psychoneuroendocrinology, 1992, 17, 497-506.

[221] Gordon, H.W., Lee, P.A. No difference in cognitive performance between phases of the menstrual cycle. Psychoneuroendocrinology, 1993, 18, 521-31. 
[222] Phillips, K., Silverman, I. Differences in the relationship of menstrual cycle phase to spatial performance on two- and three-dimensional tasks. Horm Behav, 1997, 32, 167-75.

[223] Epting, L.K., Overman, W.H. Sex-sensitive tasks in men and women: a search for performance fluctuations across the menstrual cycle. Behav Neurosci, 1998, 112, 1304-17.

[224] Hausmann, M., Slabbekoorn, D., Van Goozen, S.H., Cohen-Kettenis, P.T., Gunturkun, O. Sex hormones affect spatial abilities during the menstrual cycle. Behav Neurosci, 2000, 114, 1245-50.

[225] Maki, P.M., Rich, J.B., Rosenbaum, R.S. Implicit memory varies across the menstrual cycle: estrogen effects in young women. Neuropsychologia, 2002, 40, 518-29.

[226] Polo-Kantola, P., Portin, R., Koskinen, T., Polo, O., Irjala, K., Erkkola, R. Climacteric symptoms do not impair cognitive performances in postmenopause. Maturitas, 1997, 27, 13-23.

[227] Yaffe, K., Grady, D., Pressman, A., Cummings, S. Serum estrogen levels, cognitive performance, and risk of cognitive decline in older community women [see comments. J. Am. Geriatr. Soc., 1998, 46, 816-21.

[228] Barrett-Connor, E., Goodman-Gruen, D. Cognitive function and endogenous sex hormones in older women. J. Am. Geriatr. Soc., 1999, 47, 1289-93.

[229] Carlson, L.E., Sherwin, B.B. Higher levels of plasma estradiol and testosterone in healthy elderly men compared with age-matched women may protect aspects of explicit memory. Menopause, 2000, 7, 168-77.

[230] Yaffe, K., Lui, L.Y., Grady, D., Cauley, J., Kramer, J., Cummings, S.R. Cognitive decline in women in relation to non-protein-bound oestradiol concentrations. Lancet, 2000, 356, 708-12.

[231] Wolf, O.T., Kirschbaum, C. Endogenous estradiol and testosterone levels are associated with cognitive performance in older women and men. Horm Behav, 2002, 41, 259-66. 
Table 1 : Fluctuations in cognitive performance according to phase of menstrual cycle

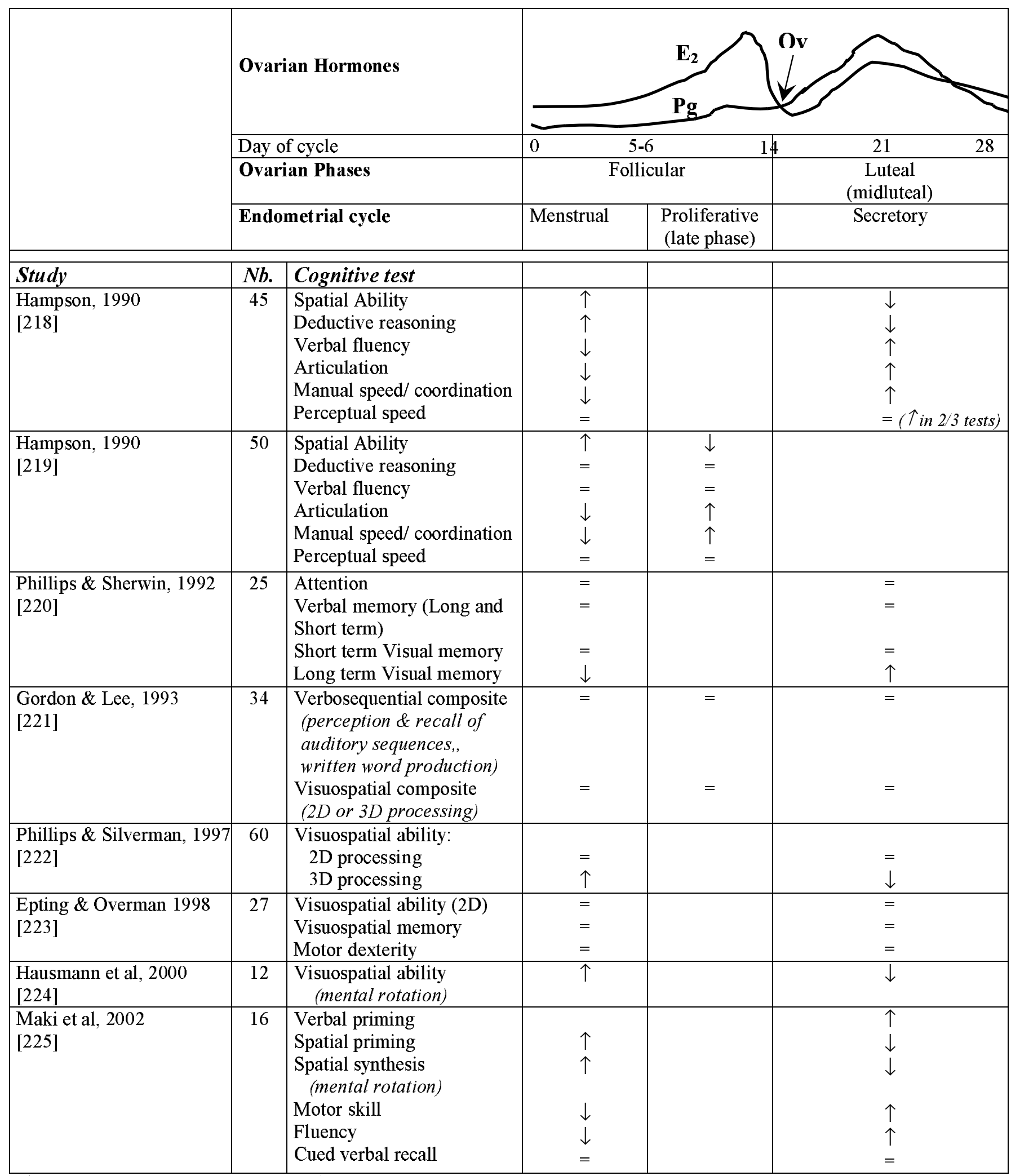

$\uparrow$ improved cognitive performances, $\downarrow$ decreased cognitive performances, $=$ no modification ; $\mathrm{E}_{2}$ : estradiol; Pg: progesterone; Ov: ovulation. 


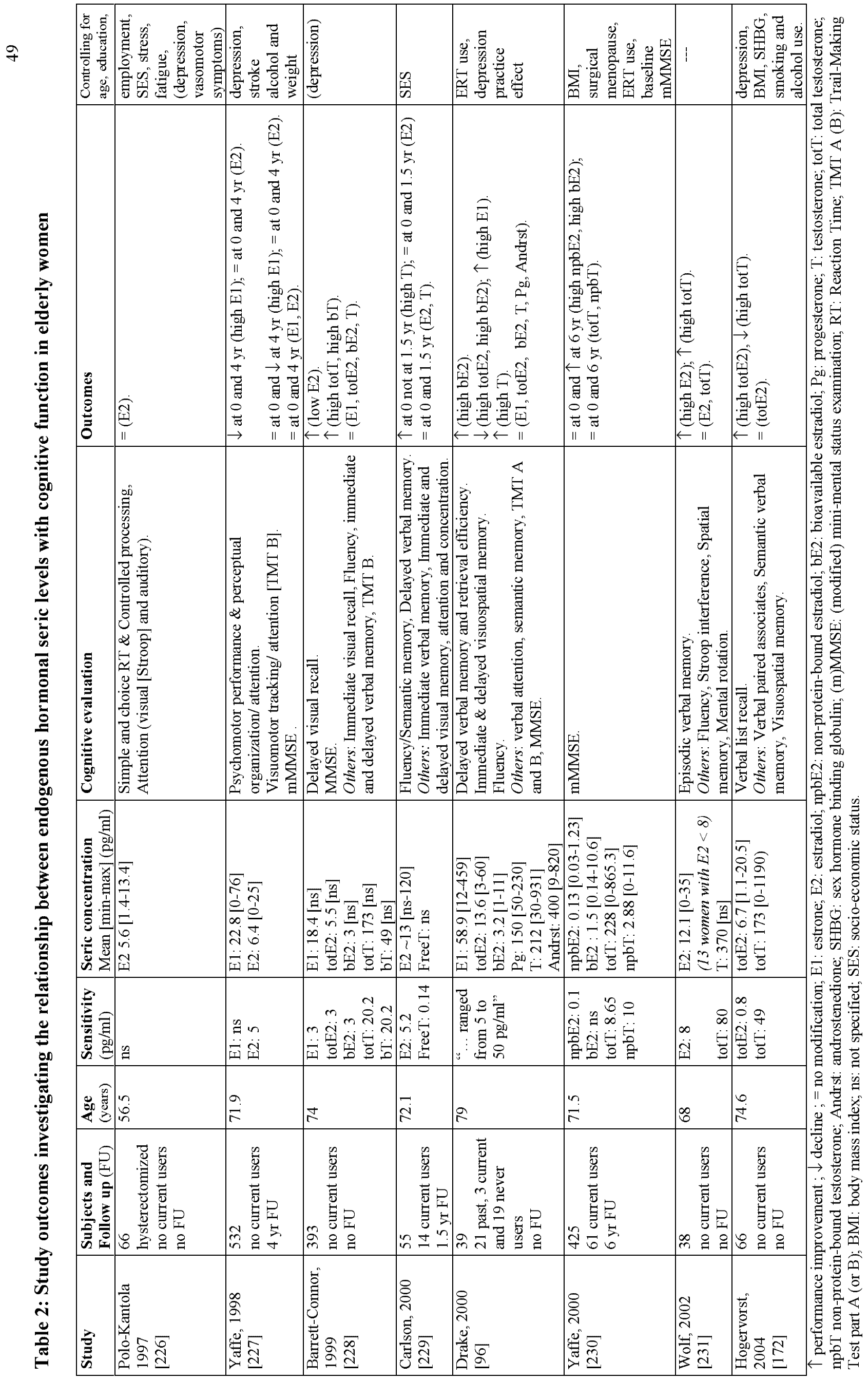

